\title{
Measurement of glyoxal using an incoherent broadband cavity enhanced absorption spectrometer
}

\author{
R. A. Washenfelder ${ }^{1,2}$, A. O. Langford ${ }^{2}$, H. Fuchs ${ }^{1,2}$, and S. S. Brown ${ }^{2}$ \\ ${ }^{1}$ Cooperative Institute for Research in Environmental Sciences, 216 UCB, University of Colorado, Boulder, CO 80309, USA \\ ${ }^{2}$ Chemical Sciences Division, National Oceanic and Atmospheric Administration, 325 Broadway, Boulder, CO 80305, USA
}

Received: 30 July 2008 - Published in Atmos. Chem. Phys. Discuss.: 29 August 2008

Revised: 24 November 2008 - Accepted: 30 November 2008 - Published: 23 December 2008

\begin{abstract}
We describe an instrument for simultaneous measurements of glyoxal (CHOCHO) and nitrogen dioxide $\left(\mathrm{NO}_{2}\right)$ using cavity enhanced absorption spectroscopy with a broadband light source. The output of a Xenon arc lamp is coupled into a $1 \mathrm{~m}$ optical cavity, and the spectrum of light exiting the cavity is recorded by a grating spectrometer with a charge-coupled device (CCD) array detector. The mirror reflectivity and effective path lengths are determined from the known Rayleigh scattering of $\mathrm{He}$ and dry zero air $\left(\mathrm{N}_{2}+\mathrm{O}_{2}\right)$. Least-squares fitting, using published reference spectra, allow the simultaneous retrieval of $\mathrm{CHOCHO}, \mathrm{NO}_{2}, \mathrm{O}_{4}$, and $\mathrm{H}_{2} \mathrm{O}$ in the 441 to $469 \mathrm{~nm}$ spectral range. For a 1-min sampling time, the precision $( \pm 1 \sigma)$ on signal for measurements of $\mathrm{CHOCHO}$ and $\mathrm{NO}_{2}$ is 29 pptv and 20 pptv, respectively. We directly compare measurements made with the incoherent broadband cavity enhanced absorption spectrometer with those from cavity ringdown instruments detecting $\mathrm{CHOCHO}$ and $\mathrm{NO}_{2}$ at 404 and $532 \mathrm{~nm}$, respectively, and find linear agreement over a wide range of concentrations. The instrument has been tested in the laboratory with both synthetic and real air samples, and the demonstrated sensitivity and specificity suggest a strong potential for field measurements of both $\mathrm{CHOCHO}$ and $\mathrm{NO}_{2}$.
\end{abstract}

\section{Introduction}

Glyoxal (CHOCHO, IUPAC name ethandial, CAS number 107-22-2) is the simplest alpha-dicarbonyl, with structure $\mathrm{HC}(\mathrm{O}) \mathrm{C}(\mathrm{O}) \mathrm{H}$, and one of the most prevalent dicarbonyls in the ambient atmosphere. Glyoxal is formed from the photooxidation of aromatic hydrocarbons (Tuazon et al., 1984; Bandow et al., 1985; Jang and Kamens, 2001) and is a mi-

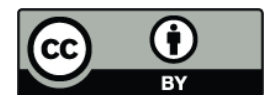

Correspondence to: R. A. Washenfelder (rebecca.washenfelder@noaa.gov) nor oxidation product of isoprene (Yu et al., 1995; Carter and Atkinson, 1996) and other biogenic species (Fick et al., 2003). Satellite measurements of glyoxal in the atmosphere suggest that oxidation of biogenic volatile organic compounds in tropical regions is an important regional source of glyoxal (Wittrock et al., 2006). There is growing laboratory evidence that heterogeneous reactions of glyoxal play an important role in the formation of secondary organic aerosol (SOA) (Hastings et al., 2005; Jang et al., 2002; Kroll et al., 2005; Liggio et al., 2005). SOA is a major contributor to fine particulate matter in urban areas, and has adverse effects on air quality and human health (Seinfeld and Pankow, 2003). Reactive uptake of glyoxal on aqueous seed aerosol may lead to significant particle growth (Kroll et al., 2005). Field measurements in Mexico City show that the atmospheric budget of glyoxal can not be balanced without an aerosol loss process (Volkamer et al., 2007). In addition to its importance in SOA formation, photolysis of glyoxal is a significant source of $\mathrm{HO}_{\mathrm{x}}\left(\mathrm{OH}+\mathrm{HO}_{2}\right)$ (Langford and Moore, 1984; $\mathrm{Zhu}$ et al., 1996; Chen and Zhu, 2003).

Despite the importance of glyoxal in SOA formation and photochemistry, until recently there have been no techniques for rapid, in situ atmospheric measurements. A standard detection method for glyoxal has been to flow air through a 2,4-dinitrophenylhydrazine (DNPH) solution, or coated solid sorbent, collecting carbonyls as hydrazone derivatives. The derivatives are then eluted with acetonitrile and measured by high pressure liquid chromatography (Fung and Grosjean, 1981; Grosjean et al., 1999; E.P.A., 1999). This method has been widely used for measurements of airborne glyoxal (Munger et al., 1995; Lee et al., 1998; Kawamura et al., 2000; Grosjean et al., 2002). A typical detection limit achieved for a two-hour sampling period with flow rate of $2 \mathrm{~L} \mathrm{~min}^{-1}$ is $30 \mathrm{pptv}$ (Francois et al., 2005). An analytical variation is analysis by gas chromatography and mass spectrometry. This method has been reported for carbonyls collected onto pentafluorophenyl hydrazine (PFPH) coated solid

Published by Copernicus Publications on behalf of the European Geosciences Union. 
sorbents, followed by thermal desorption and gas chromatographic analysis with mass spectrometric detection (GCMS) (Ho and Yu, 2004). The method has been further explored for carbonyls acquired in a mist chamber, reacted with $\mathrm{O}$ (2,3,4,5,6-pentafluorobenzyl)-hydroxylamine hydrochloride (PFBHA), and detected by gas chromatography with ion trap mass spectrometry (Spaulding et al., 2002; Spaulding et al., 2003). Measurements by these different wet chemical methods show that glyoxal levels in urban areas can be highly variable, ranging from $10 \mathrm{pptv}$ to $1 \mathrm{ppbv}$, with higher levels observed in more polluted areas.

More recently, two different spectroscopic techniques have been used for long path and in situ measurements of glyoxal. Volkamer et al. (2005a) demonstrated long path differential optical absorption spectroscopy (DOAS) in Mexico City to detect glyoxal by its structured absorption in the $420-465 \mathrm{~nm}$ spectral region. For an atmospheric path length of $4420 \mathrm{~m}$ and integration times between 2 to $15 \mathrm{~min}$, the authors report a detection limit of $150 \mathrm{pptv}$. Huisman et al. (2008) recently demonstrated a laser-induced phosphorescence technique, by exciting glyoxal at $440.25 \mathrm{~nm}$ using a tuned Ti:sapphire laser and observing the phosphorescence at $520 \mathrm{~nm}$. This is a sensitive, in situ technique with excellent specificity, but the Ti:sapphire laser is relatively expensive. The instrument has been deployed in a recent ground-based field campaign, with a reported detection limit $(S / N=3)$ of 18 pptv in $1 \mathrm{~min}$.

Another technique that has considerable potential for sensitive and specific measurement of glyoxal is Incoherent Broadband Cavity Enhanced Absorption Spectroscopy (IBBCEAS) (Fiedler et al., 2003). IBBCEAS belongs to a class of extinction measurements that exploit the long optical path lengths within optical cavities. The best known of these techniques is Cavity Ringdown Spectroscopy (CRDS). IBBCEAS differs from other methods in this class by using a relatively inexpensive continuous broadband, incoherent light source instead of a monochromatic laser. In principle, IBBCEAS is similar to previous laser-based methods for broadband CRDS (Ball and Jones, 2003) in that the light passing through a high-finesse optical cavity is dispersed with a spectrometer and analyzed using a multichannel detector. However, in contrast to the broadband CRDS methods described by Ball and Jones, IBBCEAS cavity output is measured continuously and the ringdown is not resolved in time. Spectral fitting methods can be used to retrieve multiple absorbers because spectral information is acquired simultaneously for a wide wavelength region. IBBCEAS is an excellent detection method for atmospheric trace gases with broad, structured absorptions in the visible and ultraviolet spectral regions, and is particularly useful for simultaneously determining the concentration of molecules with significant spectral overlap, such as $\mathrm{CHOCHO}$ and $\mathrm{NO}_{2}$. This method was first described in the literature by Fiedler et al. (2003). Subsequently, it has been used for laboratory measurements of a number of trace gas species, including $\mathrm{NO}_{2}$ (Ball et al.,
2004; Gherman et al., 2008; Langridge et al., 2006; Triki et al., 2008), $\mathrm{NO}_{3}$ (Ball et al., 2004; Venables et al., 2006), HONO (Gherman et al., 2008), $\mathrm{O}_{3}$ (Venables et al., 2006), and $\mathrm{I}_{2}$ (Ball et al., 2004). However, reported field measurements using this technique are very limited (e.g. Langridge et al., 2007).

In this paper, we report the first laboratory measurements of CHOCHO by IBBCEAS, together with simultaneous measurements of $\mathrm{NO}_{2}, \mathrm{H}_{2} \mathrm{O}$, and oxygen dimer $\left(\mathrm{O}_{4}\right)$. We discuss the potential application of this method for field measurements.

\section{Materials and methods}

\subsection{Description of the IBBCEAS instrument}

The IBBCEAS instrument consists of a broadband light source, collimating optics, optical filters, cavity, and grating spectrometer with a CCD array detector. A schematic of the apparatus is shown in Fig. 1a. Broadband radiation is provided by a $75 \mathrm{~W}$ Xe arc lamp in a water-cooled housing with a F/2 ellipsoidal reflector (Oriel Instruments). A cold mirror with $525 \mathrm{~nm}$ cut-off (Thorlabs FM204) and two colored glass filters (Schott Glass BG 26 and GG 420) remove light produced by the Xe arc lamp that is outside the spectral region of interest. The colored glass filters are necessary to minimize photolysis of $\mathrm{CHOCHO}$ and $\mathrm{NO}_{2}$ and to prevent degradation of the mirror reflectivity by exposure to UV radiation (Flad et al., 2006). The light is then collimated and coupled into the optical cavity using two F/1 lenses. The cavity consists of two $2.5 \mathrm{~cm}, 1 \mathrm{~m}$ radius of curvature mirrors (Advanced Thin Films) with manufacturer reported transmission of 11 parts per million (ppm) at the nominal center wavelength of $455 \mathrm{~nm}$. The mirrors are mounted at either end of a $94.4 \mathrm{~cm}$ long, $2.5 \mathrm{~cm}$ diameter PFA Teflon cell, with ports for gas input and output. Purge volumes may be used to maintain mirror cleanliness during atmospheric sampling, but were not used in these experiments, which were conducted primarily in particle-free zero air. The optical cavity is mechanically stabilized using a $2 \mathrm{~cm}$ diameter carbon rod and custom optical mounts. Fixed apertures at the entrance and exit confine the light to a $1.5 \mathrm{~cm}$ diameter at the center of the cavity.

The light that exits the cavity passes through a quartz beamsplitter and is imaged by a $2.5 \mathrm{~cm} \mathrm{~F} / 3.1$ lens onto a $0.5 \mathrm{~cm} \mathrm{~F} / 2$ lens that couples the light into a $3 \mathrm{~m}$ long $600 \mu \mathrm{m}$ optical fiber. The quartz beamsplitter is used to direct a $\mathrm{HeNe}$ laser beam into the cavity during the initial alignment. A bandpass filter, centered at $450 \mathrm{~nm}$ with full-width at halfmaximum (FWHM) of $40 \mathrm{~nm}$ (Thorlabs FB450-40), is located in front of the $F / 2$ lens. A second lens and fiber combination collects part of the light reflected by the quartz beamsplitter, to monitor the signal intensity from the Xe arc lamp. The signal intensity at $522 \mathrm{~nm}$ can be used as a scaling factor to normalize the cavity spectra prior to analysis. We did 
a
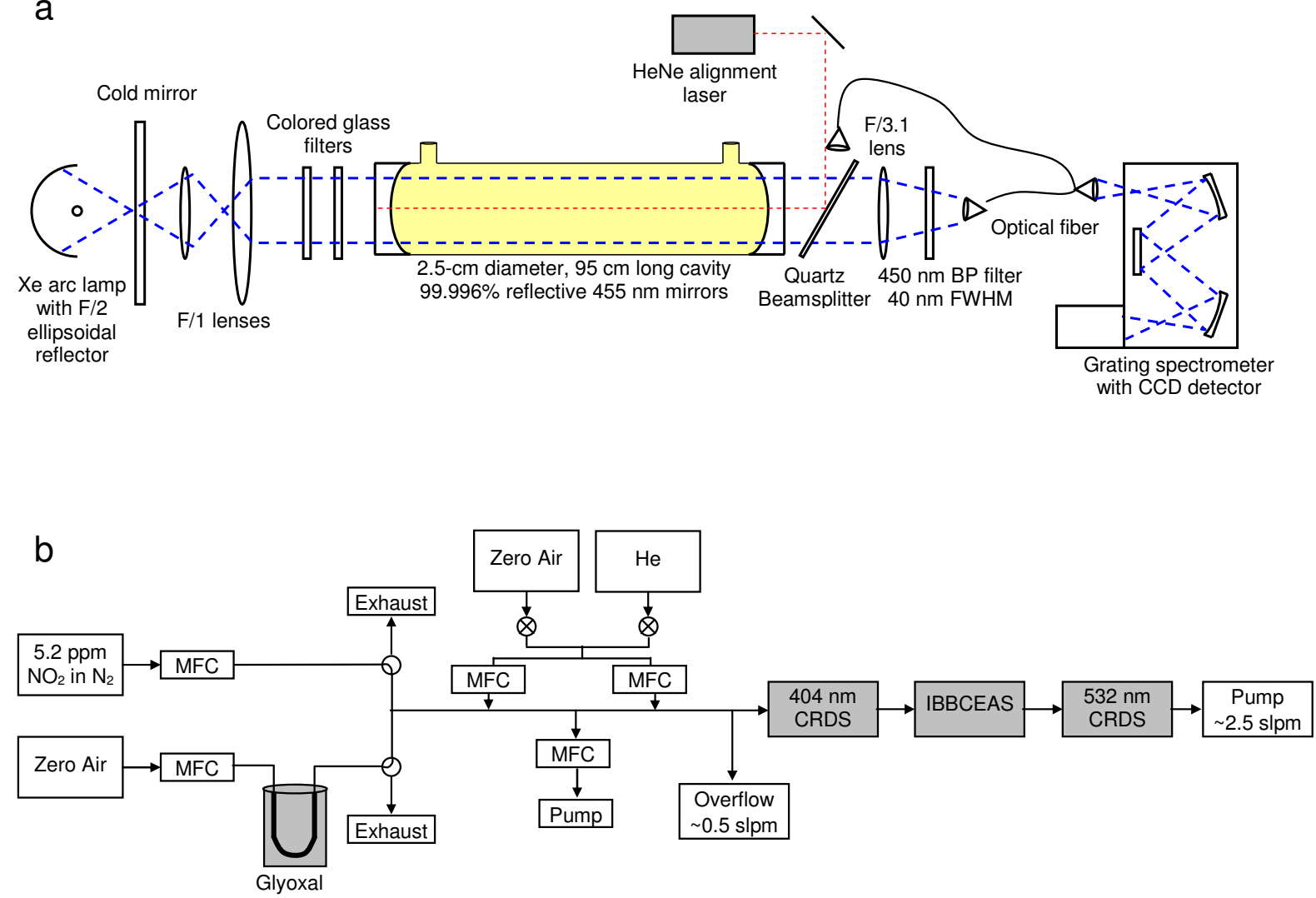

Fig. 1. (a) Schematic of the incoherent broadband cavity enhanced absorption spectrometer. The IBBCEAS instrument consists of a Xenon arc lamp, optical filters, collimating optics, cavity, and grating spectrometer. Details of the $532 \mathrm{~nm}$ cavity ringdown spectrometer can be found in Osthoff et al. (2006). The $404 \mathrm{~nm}$ cavity ringdown spectrometer will be described in a forthcoming publication (H. Fuchs, personal communication, 2008). (b) Block diagram showing gas delivery of $\mathrm{CHOCHO}$ and $\mathrm{NO}_{2}$ to the three instruments.

not observe changes in the lamp's emission spectrum as a function of time, presumably because the water-cooled housing maintained a constant temperature for the Xe arc lamp. Each of the two signal fibers is connected to an external shutter assembly consisting of a solenoid-driven shutter and a 95\% transmitting quartz beamsplitter sandwiched between two quartz collimating lenses. The collimating lenses couple the emerging cone from the $600 \mu \mathrm{m}$ sample fibers into the $750 \mu \mathrm{m}$ daisy pattern of the spectrometer feed bundle (see below). A third fiber, connected to an $\mathrm{Hg} / \mathrm{Ar}$ calibration lamp, can illuminate the quartz beamsplitter so that the output from this fiber is reflected into the spectrometer feed bundle. This configuration, with the beamsplitter on the spectrometer side of the solenoid shutter, makes it possible to acquire calibration spectra without disconnecting the sample feed fibers.

Spectra are acquired using a $150 \mathrm{~mm}$ focal length crossed Czerny-Turner spectrometer (Acton InSpectrum 150) with a 16-bit back-illuminated $250 \times 1024$ pixel CCD array detector cooled to $-20^{\circ} \mathrm{C}$ (Langford et al., 2007). The spectrometer is configured with a 1200 groove $/ \mathrm{mm}$ grating $(500 \mathrm{~nm}$ blaze $)$ rotated to give a useful spectral range from 412 to $529 \mathrm{~nm}$.
The wavelength calibration and instrument lineshape were determined using narrow $\mathrm{Hg}$ emission lines provided by a $\mathrm{Hg} / \mathrm{Ar}$ calibration lamp. A fixed slit width of $100 \mu \mathrm{m}$ was found to give a nearly Gaussian line shape with FWHM of $0.54 \mathrm{~nm}$ at $435.8 \mathrm{~nm}$. Spectra of other $\mathrm{Hg}$ lines shows that the FWHM increased with wavelength (but is constant in frequency space) with $\Delta \lambda \approx 0.58 \mathrm{~nm}$ at $455 \mathrm{~nm}$. The spectrometer was fed by a fiber bundle (Acton Model BFB-4557) composed of two leads, each consisting of seven $200 \mu \mathrm{m}$ diameter UV-VIS fibers. The two input leads were joined to form a circular "daisy" pattern (six fibers surrounding a seventh in the center) with a diameter of $735 \mu \mathrm{m}$ including cladding at the spectrometer end. The seven fibers were oriented linearly along the slit axis, with a gap of $1 \mathrm{~mm}$ between the two groups. Each of these groups illuminated a separate rectangular region $(\approx 80$ pixels tall) on the $\mathrm{CCD}$ array creating two independent channels. 
2.2 Validation of IBBCEAS CHOCHO and $\mathrm{NO}_{2}$ measurements using CRDS

The IBBCEAS measurements of $\mathrm{CHOCHO}$ and $\mathrm{NO}_{2}$ were validated using 404 and $532 \mathrm{~nm}$ cavity ringdown spectrometers already available in our laboratories. The IBBCEAS instrument has the ability to simultaneously determine multiple species that absorb in the same spectral region. Since both $\mathrm{CHOCHO}$ and $\mathrm{NO}_{2}$ absorb at $404 \mathrm{~nm}$, while only $\mathrm{NO}_{2}$ absorbs at $532 \mathrm{~nm}$, the two CRDS instruments can be used in combination to quantify one or both absorbers. We first compared the two CRDS instruments for measurements of $\mathrm{NO}_{2}$ in zero air to verify their agreement. For $\mathrm{CHOCHO}$ and $\mathrm{NO}_{2}$ mixtures, the portion of the total extinction due to $\mathrm{NO}_{2}$ can then be removed from the $404 \mathrm{~nm}$ CRDS signal using the $532 \mathrm{~nm}$ CRDS measurements. This allows the extinction signal from $\mathrm{CHOCHO}$ to be determined. Although this approach can not be used for samples containing aerosols or unknown absorbers, it does provide an independent comparison for IBBCEAS measurements of $\mathrm{CHOCHO}$ and $\mathrm{NO}_{2}$ in zero air. This allowed us to validate the IBBCEAS measurements with sufficient sensitivity over the desired concentration range, without sample concentration or dilution.

The $532 \mathrm{~nm}$ pulsed CRDS instrument used to measure $\mathrm{NO}_{2}$ concentrations has been previously described in detail, and validated against a photolysis-chemiluminescence detector (Osthoff et al., 2006). Briefly, part of the output $(\sim 1 \mathrm{~mJ})$ from a pulsed $100 \mathrm{~Hz} \mathrm{Nd:YAG} \mathrm{laser} \mathrm{is} \mathrm{passed} \mathrm{through} \mathrm{an} \mathrm{op-}$ tical isolator and collimated using a $50 \mathrm{~cm}$ focal length lens. The cavity consists of $2.5 \mathrm{~cm}$ diameter, $1 \mathrm{~m}$ radius of curvature cavity ringdown mirrors, separated by $91.5 \mathrm{~cm}$, with peak reflectivity greater than $99.999 \%$ at $532 \mathrm{~nm}$. The active sampling region is enclosed by $1.27 \mathrm{~cm}$ O.D. PFA Teflon tubing. Purge volumes are normally used to maintain mirror cleanliness during atmospheric sampling, but were not used in these experiments, which were conducted primarily in particle-free zero air. Output light from the cavity is collected using a fiber-collimating lens and a $532 \mathrm{~nm}$ bandpass filter. The photomultiplier output is digitized at $1 \mathrm{MHz}$ by a 16bit A/D converter. The precision of this instrument for $\mathrm{NO}_{2}$ is 40 pptv for 1-second data, with absolute accuracy $\pm 4 \%$ (Osthoff et al., 2006). The effective $\mathrm{NO}_{2}$ absorption crosssection obtained for this instrument is in excellent agreement with that obtained by convolving the high-resolution spectra of Vandaele et al. (2002).

The second CRDS instrument will be described in a forthcoming paper (H. Fuchs, personal communication, 2008). It consists of a diode laser centered at $403.9 \mathrm{~nm}$ (Power Technologies) with $40 \mathrm{~mW}$ output power. Custom control electronics are used to modulate the laser power output at $1.6 \mathrm{kHz}$. The laser beam is coupled into a high-finesse cavity that consists of $2.5 \mathrm{~cm}$ diameter, $1 \mathrm{~m}$ radius of curvature mirrors (Advanced Thin Films), with total loss (transmission, absorption, and scattering) of $40 \mathrm{ppm}$ at their nominal center wavelength of $404 \mathrm{~nm}$. The mirrors are mounted at either end of a $93 \mathrm{~cm}$ long cavity, with ports for input, output, and mirror purge. As with the IBBCEAS and $532 \mathrm{~nm}$ CRDS instruments, the purge volumes were not used for this experiment. Signal is detected using a Hamamatsu photomultiplier tube (HC120-05) with bandpass filter (centered at $410 \mathrm{~nm}$ with FWHM $10 \mathrm{~nm}$ ). The data is acquired with a $1 \times 10^{6}$ sample $\mathrm{s}^{-1}$ card (National Instruments, M-Series) and Labview data acquisition software. Ringdown traces were averaged over $1 \mathrm{~s}$ and then fitted to an exponential function by the Levenberg-Marquard least-square algorithm. Separate measurements using the grating spectrometer showed that the laser line was nearly Gaussian with a FWHM of $0.65 \mathrm{~nm}$. This instrument lineshape was convolved with the high-resolution cross-sections of Vandaele et al. (2002) for $\mathrm{NO}_{2}$ measurements and Volkamer et al. (2005b) for CHO$\mathrm{CHO}$ measurements.

\subsection{Preparation and delivery of $\mathrm{CHOCHO}$ and $\mathrm{NO}_{2}$}

Glyoxal was purchased commercially in a stable hydrated form (glyoxal trimer dihydrate $\geq 95 \%$ ). Pure glyoxal monomer was prepared from the solid trimer dihydrate using a method described previously (Langford and Moore, 1984; Feierabend et al., 2008). Equal masses $(\sim 5 \mathrm{~g})$ of glyoxal trimer dihydrate and solid phosphorous pentoxide $\left(P_{2} \mathrm{O}_{5} \geq 98 \%\right)$ were mixed and slowly heated under vacuum from 25 to $\sim 160^{\circ} \mathrm{C}$. A small flow of $\mathrm{He}\left(\sim 20 \mathrm{STP} \mathrm{cm}^{3} \mathrm{~min}^{1}\right)$ was passed over the heated sample and through a collection reservoir where the pure glyoxal solid was collected at $-78.5^{\circ} \mathrm{C}$. The glyoxal sample was stored at $-78.5^{\circ} \mathrm{C}$ and used without further purification.

Samples of glyoxal in zero air were prepared by flow dilution from the glyoxal trap. The reported vapor pressure of glyoxal at $-73^{\circ} \mathrm{C}$ is $\sim 0.07 \mathrm{hPa}$ (Feierabend et al., 2008), corresponding to an equilibrium vapor pressure of $66 \mathrm{ppm}$ at $1 \mathrm{~atm}$. Samples of $\mathrm{NO}_{2}$ in zero air were prepared by flow dilution from a standard cylinder containing $5.2 \mathrm{ppm} \mathrm{NO} 2$ in $\mathrm{N}_{2}$. In each case, a dynamic flow dilution system, similar to that described by Goldan et al. (1986), was used to achieve atmospherically-relevant concentrations.

As shown in Fig. 1b, the three instruments were connected in series. Flow through the instruments was controlled at $2.5 \mathrm{STPL} \mathrm{min}{ }^{-1}$ (slpm) with a mass flow controller and pump. Sample gas was provided in excess, with an inlet overflow (typically $0.5 \mathrm{slpm}$ ). Pressure and temperatures were measured by the $404 \mathrm{~nm}$ and $532 \mathrm{~nm}$ CRDS instruments, and interpolated for the IBBCEAS cell. The pressure drop was typically $10-12 \mathrm{hPa}$ for the three instruments.

\subsection{Operation of the IBBCEAS instrument}

During normal laboratory operation, the IBBCEAS and CRDS instruments are turned on at least $30 \mathrm{~min}$ prior to beginning measurements. The allows the temperature of the Xe arc lamp, lasers, and other components to stabilize. To 
characterize the noise of the Acton InSpectrum 150 CCD detector, background spectra are acquired under dark conditions. This is necessary because CCD detectors produce non-zero signal even when there is no light incident on the detector. The pixel-dependent dark signal is then scaled to the integration time and subtracted from the subsequent sample spectra. Following the acquisition of dark spectra, wavelength calibration spectra for the Acton InSpectrum 150 are acquired using the $\mathrm{Hg} / \mathrm{Ar}$ lamp described in Sect. 2.1.

Data was typically acquired for an $8 \mathrm{~h}$ period. During the experiments, individual IBBCEAS spectra were intregrated for $5 \mathrm{~s}$ with 12 individual spectra averaged, for a total data acquisition time of $1 \mathrm{~min}$. At the beginning and end of the day, $\mathrm{He}$ and zero air spectra were each acquired for $20 \mathrm{~min}$. These spectra are used to calculate mirror reflectivity, as described in Sect. 3.2. The subsequent measurements introduced concentrations of $\mathrm{NO}_{2}, \mathrm{CHOCHO}$, or combinations of the two absorbers using the flow system shown in Fig. 1b. Typically an absorber concentration was sampled for $15 \mathrm{~min}$, followed by a $10 \mathrm{~min}$ sample of zero air. The pressure stability of the laboratory measurements and the regular acquisition of zero air spectra eliminated the need to apply pressure corrections.

\section{IBBCEAS data analysis}

\subsection{Theoretical principle}

The measurement of trace gas concentrations by IBBCEAS has been described previously by Fiedler et al. (2003). Appendix A gives an alternative derivation that is specific to the zero determination method described here. The extinction due to absorption, $\alpha_{\mathrm{abs}}$, is related to the observed change in intensity transmitted through the cavity by the relationship

$\alpha_{\mathrm{abs}}(\lambda)=\left(\frac{1-R(\lambda)}{d}+\alpha_{\text {Ray }}(\lambda)\right)\left(\frac{I_{0}(\lambda)-I(\lambda)}{I(\lambda)}\right)$

where $d$ is the cavity length, $R(\lambda)$ is the mirror reflectivity, $\alpha_{\text {Ray }}$ is the total Rayleigh scattering for the mixture, $I_{0}(\lambda)$ is the reference spectrum, and $I(\lambda)$ is the measured spectrum for a cavity containing absorbing species. As discussed in Appendix A and described below, the reference spectrum $I_{0}(\lambda)$ refers to a cavity containing zero air with no other extinctions.

If the cavity contains a gas mixture with $n$ absorbers (including $\mathrm{CHOCHO}$ and $\mathrm{NO}_{2}$ ), the left hand side of Eq. (1) can be written as

$$
\begin{aligned}
\alpha_{\mathrm{abs}} & =\sum_{i}^{n} \alpha_{i}(\lambda)=\sum_{i}^{n} \sigma_{i} N_{i}=\sigma_{\mathrm{NO}_{2}}(\lambda)\left[\mathrm{NO}_{2}\right] \\
& +\sigma_{\mathrm{CHOCHO}}(\lambda)[\mathrm{CHOCHO}]+\ldots
\end{aligned}
$$

where $\sigma_{i}(\lambda)$ is the absorption cross-section and $N_{i}$ is the number density for the $i$ th absorber. The number densities for the absorbers can thus be determined through the evaluation of Eqs. (1) and (2) with a suitable set of reference spectra, $\sigma_{i}(\lambda)$.

Following this approach, we fit the total extinction, including the Rayleigh scattering, using nonlinear least-square fitting based on the Levenberg-Marquardt algorithm. IBBCEAS spectra can alternatively be analyzed using differential optical absorption spectroscopy (DOAS) techniques (Platt et al., 1979), as demonstrated by Langridge et al. (2006) for their IBBCEAS measurements of $\mathrm{NO}_{2}$. Conventional DOAS resolves the absorption cross-sections of the molecular absorbers into smooth components that change slowly with wavelength and differential absorption crosssections that change rapidly with wavelength. The relative concentrations of molecular absorbers in any two measured spectra can then be retrieved by least-squares fitting the rapidly varying part of the log of the ratio of the spectra to a linear combination of the known absorber cross-sections, while the slowly varying component (including the contributions due to Rayleigh and Mie scattering) is fit to a polynomial function. This approach is useful in situations where the two spectra include unknown contributions from Rayleigh and Mie scattering processes, such as measurements of scattered sunlight or open path measurements using an artificial light source. However, DOAS analysis techniques are unnecessary when the reference spectrum $I_{0}(\lambda)$ does not include unknown absorption or scattering, as in the present experiments. The absolute retrieval method described here significantly improves the accuracy and precision of retrievals for laboratory mixtures of different absorbers in synthetic air, and, as will be discussed below, makes it possible to retrieve spectral information about ambient aerosols in real air samples.

\subsection{Determination of mirror reflectivity}

Calculating an absorber concentration from Eq. (1) first requires accurate knowledge of the mirror reflectivity $R(\lambda)$. Unlike CRDS, which is an absolute technique equivalent to direct application of the Lambert-Beer law to measure intensity attenuation over a sample of fixed path length, CEAS and IBBCEAS are not absolute in the sense that the mirror reflectivity must be determined independently. However, if the mirror reflectivity can be accurately calibrated, then the technique is as "absolute" as other methods based on direct absorption. Cavity loss is defined as the fractional loss in light intensity per pass. For a cavity containing zero air, it includes losses due to transmission, absorption, and scattering by the mirrors, as well as Rayleigh scattering. The discussion below describes a simple and convenient method for calibrating the cavity loss.

Mirror reflectivity (or total cavity loss) can be determined from the intensity change caused by the addition of a known concentration of an absorber, such as $\mathrm{NO}_{2}$ or $\mathrm{O}_{3}$ (e.g. Langridge et al., 2006; Venables et al., 2006; e.g. Gherman et 


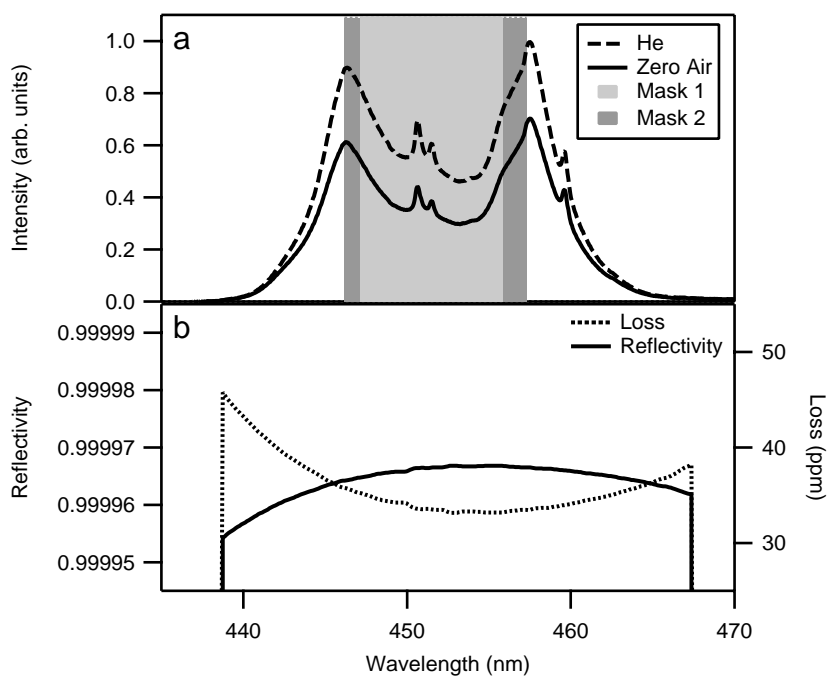

Fig. 2. (a) Representative spectra acquired with the IBBCEAS for $\mathrm{He}$ and zero air. The difference between these spectra is due to Rayleigh scattering. The broad envelope is shaped by the transmission functions of the 450-nm bandpass filter and cavity mirrors. Narrow peaks near 450 and $452 \mathrm{~nm}$ are due to Xe emission lines superimposed on the broad continuum output of the lamp. Mask 1 indicates the spectral region used for retrievals. Mask 2 indicates the spectral region used for calculation of the reflectivity. (b) Reflectivity calculated according to Eq. (1) for the He and zero air spectra shown in (a). The peak reflectivity at $455 \mathrm{~nm}$ is $99.9966 \%$ (34 ppm total loss), corresponding to an effective path length of $27.8 \mathrm{~km}$, or $17.9 \mathrm{~km}$ when the cavity contains $830 \mathrm{hPa}$ of zero air.

al., 2008), or by the addition of gases with different Rayleigh cross-sections. The advantage of the latter method is that the Rayleigh extinction varies slowly with wavelength in a well-defined manner, providing a uniform measure of mirror reflectivity across any arbitrary wavelength range. This is a simple and accurate method that can be used to determine mirror reflectivity throughout the visible and UV spectral regions. Moreover, this method can be used in any environment (field or laboratory) for a closed-cell IBBCEAS instrument. In our experiments, $R(\lambda)$ is determined from the changes in transmitted intensity due to Rayleigh scattering when the cell is filled with $\mathrm{He}$ and then zero air. Helium and zero air are useful for the calculation of $R(\lambda)$ because of the large difference between their respective Rayleigh scattering cross-sections.

Figure 2a shows spectra of $\mathrm{He}$ and zero air. The broad envelope is shaped by the transmission functions of the cavity mirrors and the $450 \mathrm{~nm}$ bandpass filter. The narrow peaks near 450 and $452 \mathrm{~nm}$ are due to Xe emission lines superimposed on the broad continuum output of the lamp. The intensity of the light that exits the cavity is dramatically reduced near $450 \mathrm{~nm}$ due to the small transmission of the mirrors in that region. The substantial decrease in transmitted intensity due to Rayleigh scattering by zero air compared to $\mathrm{He}$ is evident.
Figure $2 \mathrm{~b}$ shows the mirror reflectivity and loss curves calculated according to the equations given in the appendix, using the $\mathrm{He}$ and zero air spectra from Fig. 2b. The curves are smooth and continuous except for small irregularities near $451 \mathrm{~nm}$ that result from imperfect cancellation of the Xe emission lines. The difference between the retrieved peak reflectivity of $99.9966 \%$ at $455 \mathrm{~nm}$ (total loss of $34 \mathrm{ppm}$ ) and the manufacturer's specification of $11 \mathrm{ppm}$ loss is consistent with expected losses due to absorption and scattering in the mirror coating at this wavelength. This reflectivity corresponds to an effective path length of $27.8 \mathrm{~km}$ at $455 \mathrm{~nm}$. The same cavity, containing $830 \mathrm{hPa}$ of zero air, has an effective path length of $17.9 \mathrm{~km}$ at $455 \mathrm{~nm}$.

\subsection{Reference spectra}

Published reference spectra are used for each of the $\sigma_{i}$ components in Eq. (2). The absolute accuracies of the number densities are ultimately limited by the accuracy of the reference spectra. For our analyses, we use the high-resolution laboratory spectra of Vandaele et al. (2002) for consistency with the CRDS $\mathrm{NO}_{2}$ retrievals. Similar results are obtained using the cross-sections of Harder et al. (1997). The spectrum of Volkamer et al. (2005b) was used for CHOCHO retrievals. The spectrum of Greenblatt et al. (1990) was used for the oxygen dimer $\left(\mathrm{O}_{4}\right)$ and the cross-sections measured by Harder and Brault (1997) were used for water vapor. The reference spectra were convolved with a Gaussian function having a FWHM of $0.58 \mathrm{~nm}$ to match the spectrometer instrument lineshape. The convolved and interpolated reference spectra were iteratively shifted and stretched to minimize the fit residuals. This accounts for small errors in the interpolated and convolved basis spectra and allows for subtle changes in the spectrometer wavelength registration due to temperature and pressure changes.

The Rayleigh scattering cross-sections for He are interpolated from the measurements of Shardanand and Rao (1977) who measured the angular dependence of the light scattered by $\mathrm{He}, \mathrm{N}_{2}, \mathrm{O}_{2}$, and other gases at the argon-ion laser wavelengths of 454,488 , and $514.5 \mathrm{~nm}$. The Rayleigh crosssections for $\mathrm{N}_{2}$ and $\mathrm{O}_{2}$ in Eq. (2) are taken from the more recent extinction measurements of Sneep and Ubachs (2005) who measured the Rayleigh scattering cross-section for $\mathrm{N}_{2}$ at $470-490 \mathrm{~nm}$ and $532.2 \mathrm{~nm}$, and fit the wavelength dependence to an empirical expression $\left(\sigma_{\mathrm{Ray}} \sim \lambda^{-4.082}\right)$ that accounts for the dispersion of the refractive index and King correction factors. Sneep and Ubachs also measured the Rayleigh scattering cross-section of $\mathrm{O}_{2}$ at $532.2 \mathrm{~nm}$; we have assumed that the wavelength dependence is similar to that of $\mathrm{N}_{2}$ over our relatively narrow wavelength range. The resulting cross-sections are in good agreement $\left(<0.1 \%\right.$ for $\mathrm{N}_{2}$ and $<5 \%$ for $\mathrm{O}_{2}$ ) with those of Shardanand and Rao when the latter are extrapolated to $532.2 \mathrm{~nm}$. These experimental results are also consistent with the calculated scattering crosssections of Bodhaine et al. (1999) and Tomasi et al. (2005). 
The relative scattering cross-sections for $\mathrm{N}_{2}$ and $\mathrm{O}_{2}$ directly measured using our apparatus differ from the ratio of the published reference cross-sections by less than $1 \%$.

\section{Results}

\subsection{Measurements of $\mathrm{NO}_{2}$}

Examples of spectral retrievals for $\mathrm{NO}_{2}$ mixtures in zero air are shown in Fig. 3. Figure 3a shows a single measured spectrum (solid black points). The retrieved Rayleigh scattering extinction and total fit are shown as dashed and grey lines, respectively, for a spectrum containing $13.0 \mathrm{ppbv} \mathrm{NO}_{2}$. Figure $3 \mathrm{~b}$ shows a series of eight measured spectra (solid black points) and their spectral fits (grey lines), with $\mathrm{NO}_{2}$ concentrations ranging over three orders of magnitude from $1.1 \mathrm{ppbv}$ to $133.1 \mathrm{ppbv}$. In Fig. 3b, the fitted Rayleigh scattering has been subtracted to better display the $\mathrm{NO}_{2}$ spectral fits.

$\mathrm{NO}_{2}$ concentrations measured by the IBBCEAS and $532 \mathrm{~nm}$ CRDS instrument are shown in Fig. 4a. The concentration ranges from $0.45 \mathrm{ppbv}$ to $222 \mathrm{ppbv}$. Figure $4 \mathrm{~b}$ shows the lower concentration data, to demonstrate the precision and detection limit of the IBBCEAS $\mathrm{NO}_{2}$ retrievals. The relationship is linear over the entire concentration range, with a slope of $0.932 \pm 0.001$ and intercept of $0.17 \pm 0.05 \mathrm{ppb}$ with an $R^{2}$ value of 0.9997 . When the intercept is fixed, the slope is $0.934 \pm 0.001$ with an $R^{2}$ value of 0.9997 . Slope and intercept uncertainties are given as the fit error in each case. The IBBCEAS $\mathrm{NO}_{2}$ measurements are systematically $6.8 \%$ lower than the CRDS $\mathrm{NO}_{2}$ measurements, but this difference is within the expected range of uncertainties, as discussed in Sect. 4.4. The $1 \sigma$ standard deviation for 1-min IBBCEAS measurements of $1.13 \mathrm{ppbv} \mathrm{NO}_{2}$ is $20 \mathrm{pptv}$. This represents the $1 \sigma$ range in retrieved $\mathrm{NO}_{2}$ concentrations for a sequence of 1-min measurements with a sample of well-defined and constant composition.

For the system with highly reflective mirrors described here, the losses due to the mirrors, Rayleigh scattering, and absorption are comparable, and none of these losses can be neglected. Examination of the data in Fig. 4 allows us to directly verify the linear behavior expected from the equations in Appendix A for a range of $\mathrm{NO}_{2}$ concentrations. For a $94.4 \mathrm{~cm}$ cavity containing $830 \mathrm{hPa}$ of zero air with $R=99.9966 \%$ mirrors, the per pass fractional losses can be summarized as $34 \mathrm{ppm}$ mirror loss and $19 \mathrm{ppm}$ Rayleigh scattering loss. When 5 ppbv of $\mathrm{NO}_{2}$ is introduced to the cavity, the additional per pass loss due to $\mathrm{NO}_{2}$ is $4.2 \mathrm{ppm}$. With 200 ppbv of $\mathrm{NO}_{2}$, the loss per pass due to $\mathrm{NO}_{2}$ is $167 \mathrm{ppm}$, and this dominates the losses in the system. Figure 4 shows no evidence for non-linearity when the absorbing species dominates the cavity losses. This is consistent with the derivations presented in Appendix A.
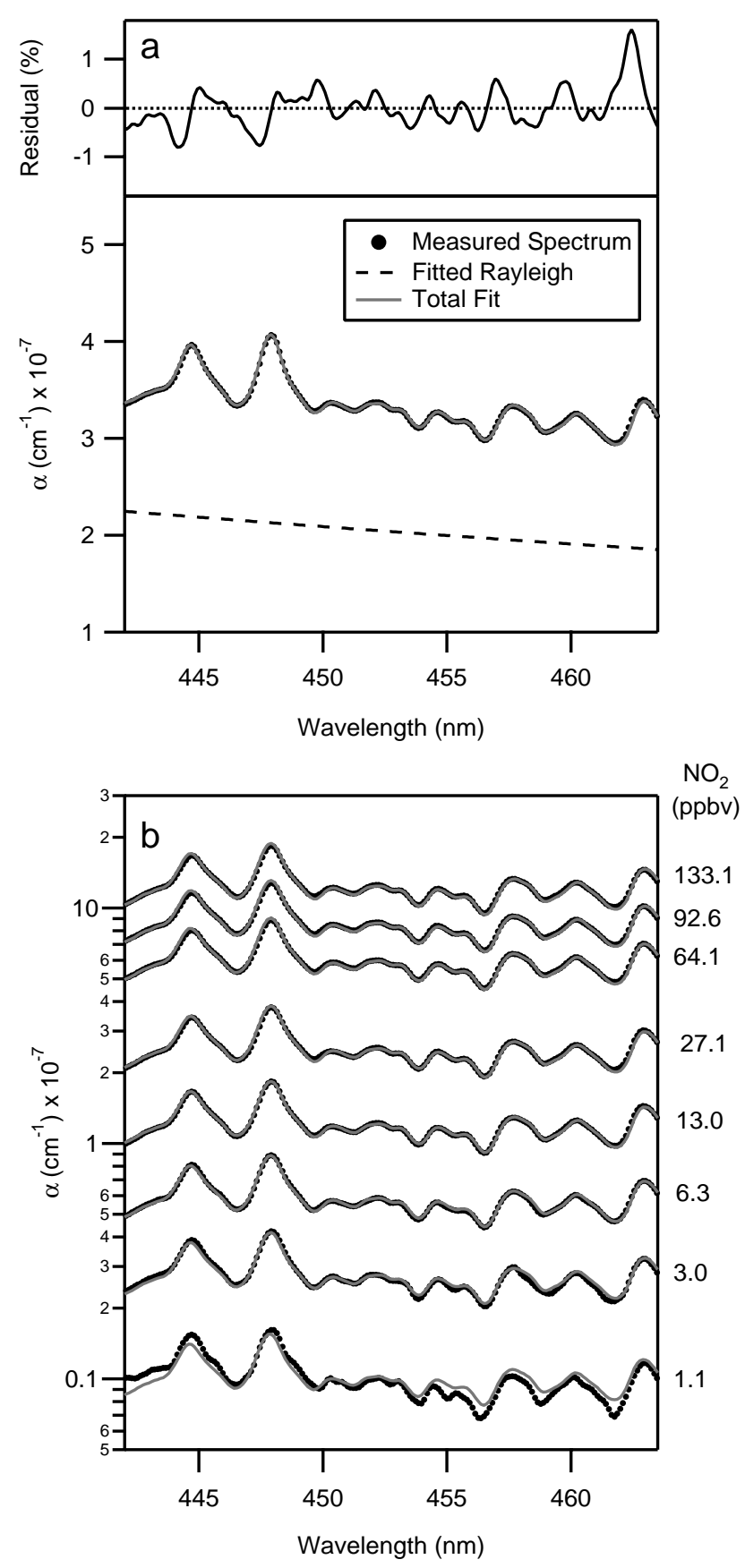

Fig. 3. (a) Example of $\alpha_{\mathrm{abs}}$ calculated for a single measured $\mathrm{NO}_{2}$ spectrum (solid black points). The contribution from Rayleigh scattering (dashed line) and the total fit (grey line) are shown. The residual indicates the fitting error. The retrieved $\mathrm{NO}_{2}$ concentration is 13.0 ppbv. (b) Examples of $\alpha_{\text {abs }}$ calculated for a series of spectra with different $\mathrm{NO}_{2}$ concentrations (solid black points) and the corresponding spectral fits (grey lines). The fitted Rayleigh scattering has been subtracted to better display the $\mathrm{NO}_{2}$ spectral fits. 

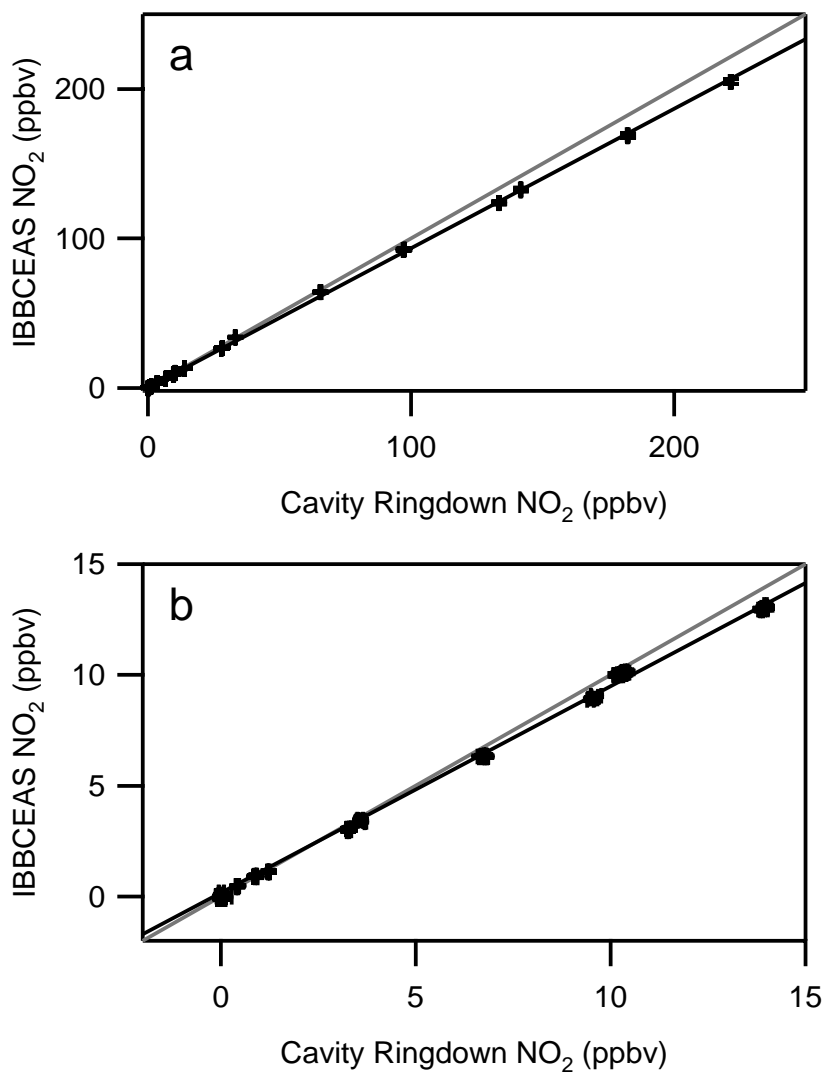

Fig. 4. (a) Correlation plot comparing $\mathrm{NO}_{2}$ measurements from $0.45-222$ ppbv acquired by the IBBCEAS instrument and the $532 \mathrm{~nm}$ CRDS. Measurements are averaged over similar 1-min time intervals. The slope is $0.932 \pm 0.001$ (black line). The one-to-one line is shown in grey. (b) Expanded view of the $0-15$ ppbv $\mathrm{NO}_{2}$ data shown in (a). The $1 \sigma$ standard deviation for 1-min IBBCEAS measurements with 1.13 ppbv $\mathrm{NO}_{2}$ is 20 pptv.

\subsection{Measurements of $\mathrm{CHOCHO}$}

Examples of spectral retrievals for glyoxal mixtures in zero air are shown in Fig. 5. Figure 5a shows a single measured spectrum (solid black points). The retrieved Rayleigh scattering extinction and total fit are shown as dashed and grey lines, respectively, for a spectrum containing $1.8 \mathrm{ppbv}$ glyoxal. Figure $5 \mathrm{~b}$ shows a series of three measured glyoxal spectra (solid black points) and their calculated fits (grey lines). In Fig. 5b, the fitted Rayleigh scattering has been subtracted to better display the glyoxal spectral fits.

Measurements of glyoxal were acquired simultaneously by the IBBCEAS and $404 \mathrm{~nm}$ CRDS during a nine-hour period. Glyoxal was introduced over a range of concentrations from $0.4 \mathrm{ppbv}$ to $29.5 \mathrm{ppbv}$. Figure $6 \mathrm{a}$ shows a portion of the time series with the lowest concentrations. The long equilibrium time constant for glyoxal addition is a consequence of the large flow dilution and does not indicate losses in the inlet or flow system. The $1 \sigma$ standard deviation for 1-min IB-
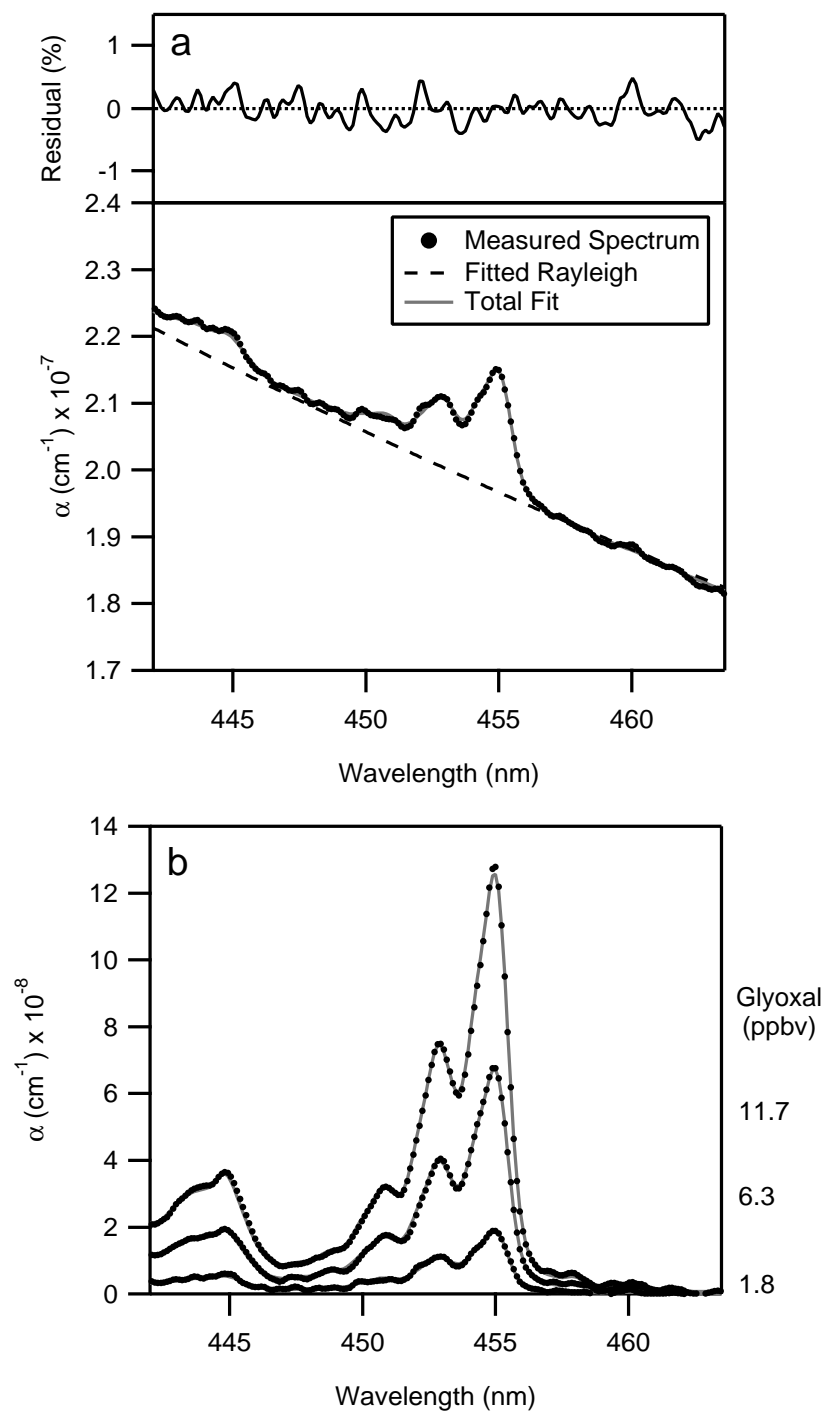

Fig. 5. (a) Example of $\alpha_{\text {abs }}$ calculated for a single measured CHO$\mathrm{CHO}$ spectrum (solid black points). The contribution from Rayleigh scattering (dashed line) and the total fit (grey line) are shown. The residual indicates the fitting error. The retrieved $\mathrm{CHOCHO}$ concentration is 1.8 ppbv. (b) Examples of $\alpha_{\text {abs }}$ calculated for a series of spectra with different $\mathrm{CHOCHO}$ concentrations (solid black points) and the corresponding spectral fits (grey lines). The fitted Rayleigh scattering has been subtracted to better display the CHOCHO spectral fits.

BCEAS measurements of 4.5-ppbv glyoxal is $29 \mathrm{pptv}$. This represents the $1 \sigma$ range in retrieved glyoxal concentrations for a sequence of 1-min measurements with a sample of welldefined and constant composition. This puts the IBBCEAS instrument in the range of sensitivity necessary for ambient concentrations, which range from $10 \mathrm{pptv}$ to $2 \mathrm{ppbv}$. The correlation plot of the measurements is shown in Fig. 6b. The slope is $0.948 \pm 0.003$ and the intercept is $-0.04 \pm 0.02 \mathrm{ppbv}$, with an $R^{2}$ value of 0.997 . The linear agreement between 
the two measurements is excellent, but the discrepancy in the slope of $5.2 \%$ is similar to that observed in the measurements of $\mathrm{NO}_{2}$.

The $404 \mathrm{~nm}$ CRDS instrument demonstrates 1-min measurements of glyoxal with a $1 \sigma$ standard deviation of $135 \mathrm{ppt}$. The CRDS detection limit could be improved by selecting a diode laser with output near the peak of the glyoxal absorption band, achieving results comparable to the IBBCEAS in the laboratory. However, the CRDS instrument does not provide an atmospheric measurement that is specific to glyoxal because it measures the total extinction by all absorbers at a single wavelength. Overlap between the $\mathrm{CHOCHO}$ and $\mathrm{NO}_{2}$ spectral absorptions means that under ambient conditions, this CRDS instrument will measure $\mathrm{NO}_{2}$ with $\mathrm{CHO}$ $\mathrm{CHO}$ absorption present as a small interference.

\subsection{Simultaneous measurements of $\mathrm{CHOCHO}$ and $\mathrm{NO}_{2}$}

Real atmospheric air samples will generally contain both $\mathrm{CHOCHO}$ and $\mathrm{NO}_{2}$ at varying mixing ratios. Accurate, simultaneous retrieval of both will be an important operating characteristic for an IBBCEAS field instrument. Published DOAS measurements, using spectra with similar resolution ( $\sim 0.4 \mathrm{~nm}$ FWHM) and shorter path length $(4.4 \mathrm{~km})$ have been used to retrieve $\mathrm{CHOCHO}$ concentrations between 0.15-1.8 ppbv with $\mathrm{NO}_{2}$ background concentrations up to $80 \mathrm{ppbv}$ (Volkamer et al., 2005a).

As shown in the block diagram in Fig. $1 \mathrm{~b}$ and described in the experimental section, our laboratory flow system can be used to introduce mixtures of $\mathrm{CHOCHO}$ and $\mathrm{NO}_{2}$ to the IBBCEAS instrument, and to independently measure both compounds with the two CRDS instruments. Figure 7a shows a measurement sequence where $\mathrm{NO}_{2}$ is first introduced, then CHOCHO is introduced, then $\mathrm{NO}_{2}$ is removed, and finally $\mathrm{CHOCHO}$ is removed. The measurement sequence is then repeated with lower concentrations of $\mathrm{CHOCHO}$ and $\mathrm{NO}_{2}$. For the IBBCEAS instrument, the step changes of $15 \mathrm{ppbv}$ and 7.5 ppbv $\mathrm{NO}_{2}$ shown in Fig. 7a change the quantitative retrieval of $\mathrm{CHOCHO}$ by no more than $4.5 \%$. The IBBCEAS measurements of $\mathrm{CHOCHO}$ and $\mathrm{NO}_{2}$ (blue and black) are compared to the CRDS measurements (light blue and grey) in Fig. $7 \mathrm{~b}$ and c. The $532 \mathrm{~nm}$ CRDS measures $\mathrm{NO}_{2}$ directly, and $\mathrm{CHOCHO}$ was determined by correcting the total extinction at $404 \mathrm{~nm}$ for the $\mathrm{NO}_{2}$ absorption. The measurement of CHOCHO by CRDS is less precise than the measurement by IBBCEAS, and demonstrates the advantage that the IBBCEAS has in observing a broad spectral range to simultaneously retrieve multiple absorbers.

4.4 Precision and accuracy of the $\mathrm{CHOCHO}$ and $\mathrm{NO}_{2}$ retrievals

As described in Sect. 4.1 and 4.2, the $1 \sigma$ standard deviation for spectral retrievals of $\mathrm{CHOCHO}$ and $\mathrm{NO}_{2}$ is 29 and 20 pptv, respectively. For retrievals in zero air containing no
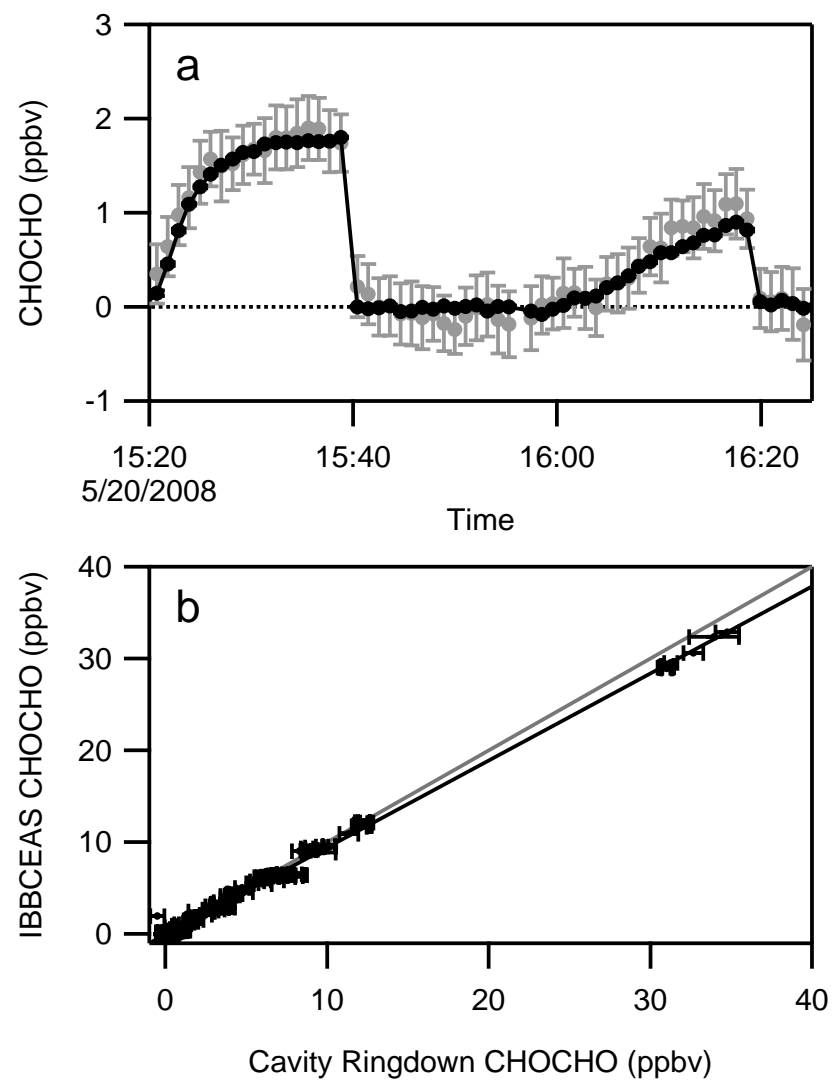

Fig. 6. (a) Subset of a 9-h comparison of CHOCHO measurements by the IBBCEAS (solid black points) and $404 \mathrm{~nm}$ CRDS instruments (solid grey points), showing the smallest measured concentrations. The long equilibrium time constant for $\mathrm{CHOCHO}$ is a consequence of the large flow dilution and does not indicate losses in the inlet or flow system. The $1 \sigma$ standard deviation for 1min IBBCEAS measurements with 4.4-ppbv CHOCHO is 29 pptv. (b) Correlation plot comparing $\mathrm{CHOCHO}$ measurements from 0.4 29.3 ppbv acquired by the IBBCEAS instrument and the $532 \mathrm{~nm}$ CRDS. Measurements are averaged over similar 1-min time intervals. The slope is $0.947 \pm 0.003$ (black line). The one-to-one line is shown in grey.

absorber, the observed $1 \sigma$ scatter around zero is consistent with the precision on signal. For a detection limit defined as $2 \sigma$, the IBBCEAS detection limit is 58 pptv $\mathrm{CHOCHO}$ and $40 \mathrm{pptv} \mathrm{NO}_{2}$ in 1-min acquisition time. The precision of spectral retrievals is limited by noise in the spectra, because the system is shot-noise limited at the CCD detector. The poor coupling of the Xe arc lamp output through the cell is the primary signal-to-noise limitation in the present measurements. In the future, greater precision could be achieved by using an Xe arc lamp with improved coupling into the optical cavity or higher power. Currently, the precision can be improved by further averaging the 1-min spectra or retrieved concentrations. 

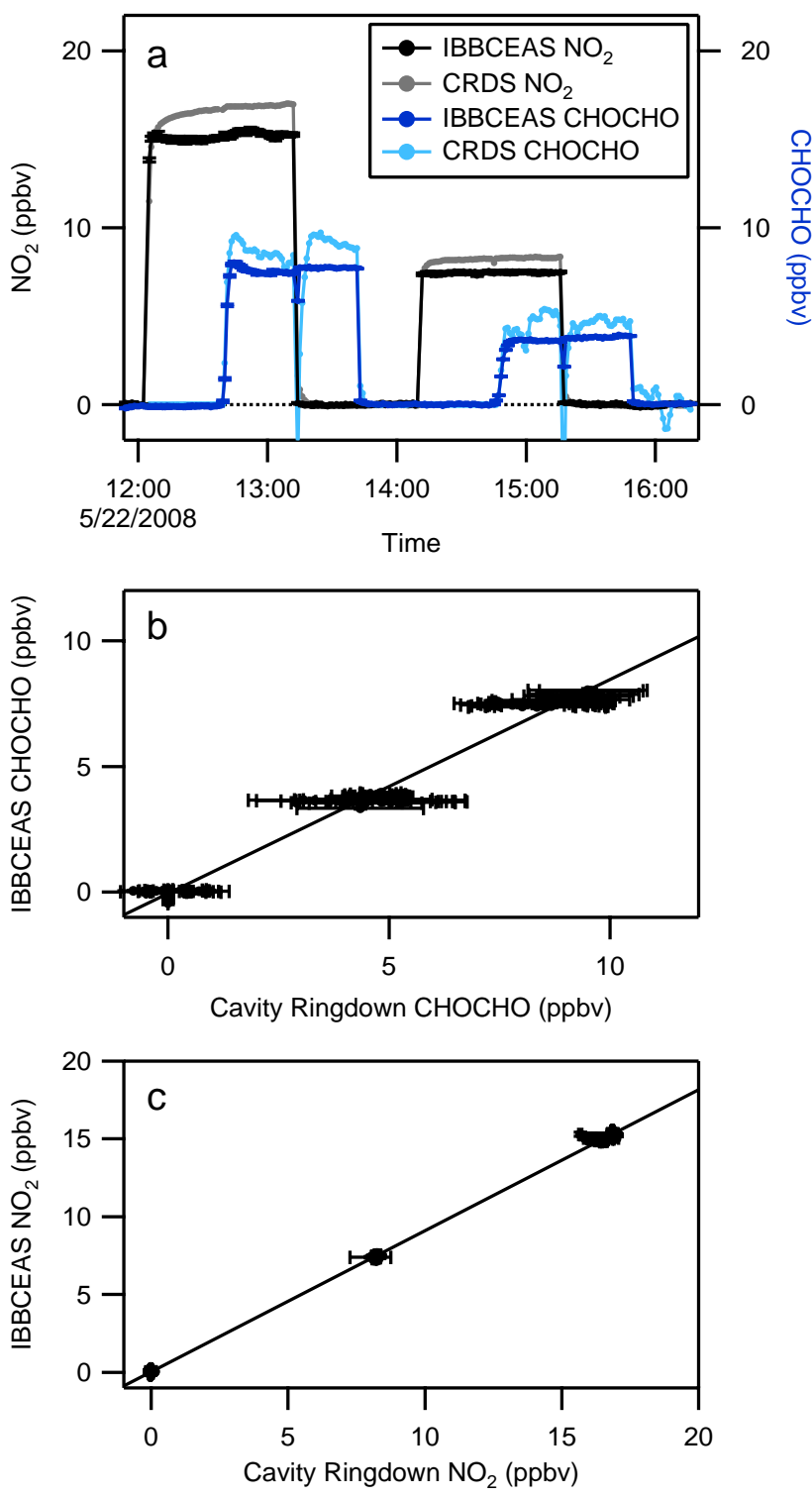

Fig. 7. (a) A series of $\mathrm{CHOCHO}$ and $\mathrm{NO}_{2}$ mixtures measured during a five hour period. Dark blue and black symbols show the CHO$\mathrm{CHO}$ and $\mathrm{NO}_{2}$ concentrations determined using IBBCEAS. Light blue and grey symbols show the $\mathrm{CHOCHO}$ and $\mathrm{NO}_{2}$ concentrations determined using the $532 \mathrm{~nm}$ and $404 \mathrm{~nm}$ CRDS instruments. (b) Correlation plot showing $\mathrm{NO}_{2}$ measurements by the IBBCEAS and $532 \mathrm{~nm}$ CRDS. (c) Correlation plot showing CHOCHO measurements by the IBBCEAS and $404 \mathrm{~nm}$ CRDS measurement corrected for $\mathrm{NO}_{2}$ absorption.

The absolute accuracy of the retrievals is limited by our knowledge of the Rayleigh scattering cross-section for zero air, Rayleigh scattering cross-section for $\mathrm{He}$, absorption cross-sections for $\mathrm{CHOCHO}$ and $\mathrm{NO}_{2}$, sample pressure, and temperature. The Rayleigh scattering cross-sections for zero air and $\mathrm{He}$ are used to calculate the mirror reflectivity. The uncertainty in the Rayleigh scattering cross-section for zero air is $\pm 2 \%$. The uncertainty of the Rayleigh scattering crosssection for $\mathrm{He}$ is similar, but this value makes a minor contribution to the total uncertainty. The uncertainty of the CHO$\mathrm{CHO}$ and $\mathrm{NO}_{2}$ absorption cross-sections are 5\% (Volkamer et al., 2005b) and 4\% (Vandaele et al., 2002), respectively. The uncertainty of pressure and temperature are $\pm 0.5 \%$ and $\pm 0.7 \%$. Addition of these uncertainties in quadrature gives a total slope uncertainty of $\pm 5.5 \%$ for $\mathrm{CHOCHO}$ and $\pm 4.6 \%$ for $\mathrm{NO}_{2}$. The reported accuracy of the well-characterized $532 \mathrm{~nm}$ CRDS instrument is $\pm 4 \%$ for $\mathrm{NO}_{2}$ (Osthoff et al., 2006), and the linear agreement between the IBBCEAS and CRDS $\mathrm{NO}_{2}$ measurements $(0.932 \pm 0.001)$ falls within the combined uncertainty of the two instruments. As shown in Fig. 4, the IBBCEAS $\mathrm{NO}_{2}$ measurements are lower than the CRDS at all concentrations, and there is no evidence of nonlinearity. Apart from the absorption cross-sections, each of the uncertainties is common to the $\mathrm{CHOCHO}$ and $\mathrm{NO}_{2}$ retrievals, which may explain why the IBBCEAS measurements of both are low compared to the CRDS measurements. If we were to regard the $\mathrm{NO}_{2}$ measurement as a calibration of mirror loss, following the alternative approach described in Sect. 3.2 (Gherman et al., 2008; Langridge et al., 2006; Venables et al., 2006), the IBBCEAS and CRDS measurements of $\mathrm{CHOCHO}$ would be consistent within $1.5 \%$.

\subsection{Initial tests to assess the potential for a $\mathrm{CHOCHO}$ field instrument}

The demonstrated precision of the glyoxal measurements under controlled laboratory conditions shows that there is a strong potential for field measurements based on this method. Such an instrument would have numerous advantages, including simplicity of operation, small size, low power consumption, and construction from relatively inexpensive components. Potential challenges for IBBCEAS measurements of glyoxal include: (i) accurate retrieval of glyoxal in the presence of large background absorptions due to other species; and (ii) wall loss of glyoxal in a closed cell configuration, such as the one described here. Tests to address these concerns are described below.

In addition to the $\mathrm{NO}_{2}, \mathrm{CHOCHO}, \mathrm{O}_{4}$, and Rayleigh extinctions discussed previously, ambient measurements of the $441-469 \mathrm{~nm}$ spectral region will include the water vibration-rotation lines of the $4 v_{1}+3 v_{3}$ and $5 v_{1}+2 v_{3}$ overtone bands. The water band is centered near $442.6 \mathrm{~nm}$ and is a relatively minor absorber, with integrated band intensity $4.05 \times 10^{-24} \mathrm{~cm}^{-1} \mathrm{~cm}^{2}$ molec (Harder and Brault, 1997). At $830 \mathrm{hPa}, 40^{\circ} \mathrm{C}$, and $100 \%$ relative humidity, the expected water extinction at $442.6 \mathrm{~nm}$ is $4.85^{\circ} 10^{-8} \mathrm{~cm}^{-1}$ or $4.6 \mathrm{ppm}$ per pass. We have measured humidified zero air to observe this potential spectral interference and to determine the accuracy of our water retrievals. Following the retrieval method described in Sect. 3.3, the $1 \sigma$ standard deviation for 1-min water retrievals is 0.84 parts per thousand (ppthv) for an average 
concentration of $12.85 \mathrm{ppthv}$. There is no evidence that the weak water absorption lines interfere with $\mathrm{CHOCHO}$ and $\mathrm{NO}_{2}$ retrievals.

Additional minor absorbers in the $441-469 \mathrm{~nm}$ spectral region include ozone $\left(\mathrm{O}_{3}\right)$, iodine monoxide (IO), and methyl glyoxal $\left(\mathrm{CH}_{3} \mathrm{COCOH}\right)$. The optical extinction due to these three species over typical ambient concentrations is less than the detection limit of the IBBCEAS instrument (currently $4 \times 10^{-10} \mathrm{~cm}^{-1}$ ). The expected extinction for ozone, with cross-section of $2.18 \times 10^{-22} \mathrm{~cm}^{2}$ at $455 \mathrm{~nm}$ (Sander et al., 2006) and a typical concentration of $50 \mathrm{ppb}$, is $2.2 \times 10^{-10} \mathrm{~cm}^{-1}$. If a correction is necessary, ozone concentrations can be independently measured using a standard, commercial ozone monitor and the smoothly-varying ozone cross-section can be subtracted from the IBBCEAS spectra. Iodine monoxide is present in marine environments or near salt flats, with a typical peak daytime concentration of 1.4 pptv (Read et al., 2008). The expected extinction for IO with a $4.57 \times 10^{-18} \mathrm{~cm}^{2}$ cross-section at $455 \mathrm{~nm}$ (Sander et al., 2006) is $1.3 \times 10^{-10} \mathrm{~cm}^{-1}$. This could produce a spectral interference, but only in or near marine environments. Methyl glyoxal is present in the atmosphere with concentrations comparable to glyoxal (Grosjean et al., 2002; Lee et al., 1998), although its cross-section at $455 \mathrm{~nm}$ is approximately 14 times smaller. The expected extinction for methyl glyoxal, with a $3.69 \times 10^{-20} \mathrm{~cm}^{-2}$ cross-section at $455 \mathrm{~nm}$ (Sander et al., 2006) and concentration of $200 \mathrm{ppt}$, is $1.5 \times 10^{-10} \mathrm{~cm}^{-1}$.

Apart from spectral interferences, water presents another challenge for closed-cell IBBCEAS measurements. Glyoxal is readily lost to surfaces under humid sampling conditions (Kroll et al., 2005). We measured glyoxal in humidified zero air, to examine losses to Teflon and metal surfaces. At relative humidity $72.0 \%$, we observe a glyoxal loss of $5.0 \% \pm 1.0 \%$ for the current flow system. Since actual atmospheric sampling will require measurements over a wide range of RH, construction of a closed-cell field instrument will require careful characterization of this potential artifact and design of an inlet system that minimizes wall contact and loss.

As a preliminary test of the potential of our approach for a field instrument, ambient laboratory air was sampled with and without a Teflon filter in place. A closed-cell field instrument will likely have an inlet filter for optimum sensitivity to $\mathrm{CHOCHO}$ and $\mathrm{NO}_{2}$, because aerosol extinction would limit the effective path length and compromise the calibration method. Filtering the air sample could result in losses due to irreversible glyoxal uptake to accumulated aerosol. An automated filter changer has been successfully developed to address a similar issue for $\mathrm{N}_{2} \mathrm{O}_{5}$ (Dube et al., 2006) and can be applied to sampling glyoxal as well. Figure 8 shows time series of the retrieved concentrations of $\mathrm{NO}_{2}, \mathrm{CHOCHO}$, and $\mathrm{H}_{2} \mathrm{O}$ over a 60 -min period. Room air was sampled during two intervals, first with an aerosol filter and then without an aerosol filter. The systems were flushed with zero air dur-

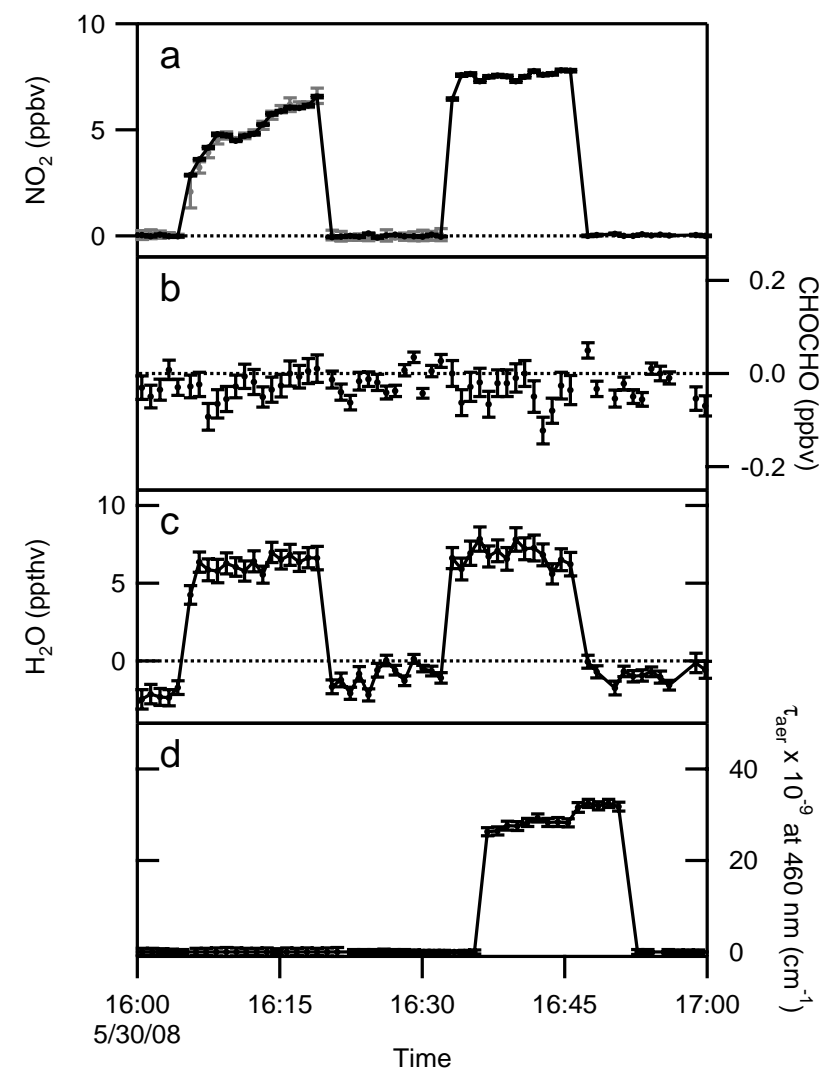

Fig. 8. Spectral retrievals for ambient laboratory air. Plot shows a sequence of measurements: dry zero air, ambient laboratory air sampled with a Teflon aerosol filter, dry zero air, ambient laboratory air sampled without an aerosol filter, and finally dry zero air. (a) IBBCEAS NO $\mathrm{N}_{2}$ measurements (black symbols) varied between 37 ppbv, consistent with the expected range of values. $532 \mathrm{~nm}$ CRDS $\mathrm{NO}_{2}$ measurements (grey symbols) are also shown for filtered air. (b) $\mathrm{CHOCHO}$ remained at or near the detection limit. (c) $\mathrm{H}_{2} \mathrm{O}$ was present at approximately 7 ppthv. (d) Aerosol extinction at $460 \mathrm{~nm}$.

ing the remaining periods. The latter configuration exposes the tubing, absorption cells, and mirrors to modest levels of aerosol particles, as well as $\mathrm{NO}_{2}, \mathrm{H}_{2} \mathrm{O}$, and perhaps other unknown absorbers that are not included in our retrievals. For these experiments, the mirror reflectivity was determined using the He and zero air Rayleigh scattering calibration described in Sect. 3.2. For the retrievals, the Rayleigh contribution to the total extinction was fixed. Figure 8a shows that the laboratory air contained 3 to $7 \mathrm{ppbv}$ of $\mathrm{NO}_{2}$, within the expected range of values. Grey symbols show the $\mathrm{NO}_{2}$ concentration determined simultaneously by the $532 \mathrm{~nm}$ CRDS for filtered air. CHOCHO remained near or below the detection limit $(\leq 0.05$ ppbv) while water was present at 7 ppthv. Subsequent work has shown that baseline drift during ambient measurements can be minimized by increasing the frequency of zero air and Helium reference measurements. The ability of the IBBCEAS to retrieve $\mathrm{NO}_{2}, \mathrm{CHOCHO}$, and $\mathrm{H}_{2} \mathrm{O}$ for ambient samples supports the expectation that this technique will be suitable for field measurements. 
Lastly, we note that the measurements without the aerosol filter demonstrate the capability of IBBCEAS for determination of aerosol optical properties. Since the only other broad extinction feature should be that due to Mie scattering by particles, the least-squares retrieval includes retrieval of the aerosol optical extinction, as shown in Fig. 8d. The apparent aerosol extinction is negligible except when laboratory air is sampled without an aerosol filter.

\section{Summary and conclusions}

Using the IBBCEAS technique in the laboratory, we report 1 -min measurements of $\mathrm{CHOCHO}$ and $\mathrm{NO}_{2}$ with $1 \sigma$ precision of 29 and $20 \mathrm{ppt}$, respectively. This precision has been achieved in a closed cell system, using Rayleigh scattering by He and zero air as a calibration for mirror reflectivity and total cavity loss, and using absolute spectral retrievals rather than DOAS-type retrievals. IBBCEAS is a simple, inexpensive, non-invasive, and rapid instrumental method. It offers advantages over the established wet-chemical measurement methods for glyoxal, which require pre-collection and concentration prior to analysis. The IBBCEAS technique has potential applications for laboratory experiments of glyoxal process chemistry.

Initial laboratory tests of the feasibility of IBBCEAS for field measurements of glyoxal have shown that the spectral retrievals are insensitive to the presence of water vapor, and that wall uptake as a function of relative humidity is modest but measurable. Further work will include construction and testing of a field instrument. In addition to measurements of gas-phase species, the use of absolute retrieval methods rather than DOAS methods allows for measurements of the total aerosol extinction.

\section{Appendix A}

\section{Relationship between trace gas extinction and cavity transmission}

The relationship between the transmitted intensity and extinction within an optical cavity has been derived in differential form and described previously (e.g. Scherer et al., 1997; Brown et al., 2000; Paul et al., 2001). It is reconsidered here from first principles in part because our instrument differs from other descriptions in the relative importance of intensity losses due to imperfect mirror reflectivity and Rayleigh scattering of air within the cavity. One consequence is that the reference or zero intensity must be well-defined, as described below.

For an external light source with intensity $I_{\text {source }}$, the time rate of change of light intensity within an optical cavity, $I_{\text {in }}$, depends on the efficiency with which the light source couples into the cavity and the intensity losses due to mirror transmission, Rayleigh and Mie scattering by gases and particles within the cavity, and absorption due to trace gases. This is summarized by

$$
\begin{gathered}
\frac{d I_{\text {in }}(\lambda)}{\mathrm{dt}}=c\left(-\frac{1-R(\lambda)}{d}-\alpha_{\text {Ray }}(\lambda)-\frac{L_{S}}{d} \alpha_{\text {Mie }}(\lambda)-\frac{L_{S}}{d}\right. \\
\left.\sum_{i} \alpha_{i}(\lambda)\right) I_{\text {in }}(\lambda)+c k_{S} I_{\text {source }}(\lambda)
\end{gathered}
$$

where $R, d$, and $L_{S}$ are the mirror reflectivity, separation, and length over which the sample is present in the cavity, respectively, $c$ is the speed of light, $\alpha_{\mathrm{Ray}}, \alpha_{\mathrm{Mie}}$, and $\alpha_{i}$ are the Beer's law extinction coefficients for Rayleigh scattering, Mie scattering, and absorption due to the $i$ th trace gas, respectively, and $k_{S}$ is an arbitrary constant to describe the coupling efficiency of the source intensity into the cavity. In each case, the extinction coefficient $\alpha_{i}(\lambda)=N_{i} \sigma_{i}(\lambda)$, where $N$ is the absorber number density and $\sigma(\lambda)$ is the absorption or scattering cross-section. The factor $L_{S} / d$ is important if purge volumes are used to separate the sample volume from the mirrors in order to keep them clean. In the current experiment, these purge volumes were not used (see text), so this factor is unity and can be neglected. Equation (A1) is valid in the limit where the sum of losses due to mirrors, scattering, and absorption are small, such that the light makes many passes within the cavity. If so, the finite time step of a single pass (or round trip) within the cavity, $\Delta t$, may be regarded as the differential, $d t$. Light intensity transmitted through the rear mirror of the cavity is directly proportional to the light intensity within the cavity, such that the observed intensity external to the cavity, I, may be obtained from Eq. (A1) through multiplication by an arbitrary constant. In an IBBCEAS instrument, transmitted intensity is observed after Eq. (A1) has reached steady state between the source input and the cavity losses, such that the differential goes to zero. In this case the proportionality constant between $I$ and $I_{\text {in }}$ may be neglected.

In what follows, we consider the case of a sample containing no particles, such that the Mie scattering extinction term may be neglected. If information regarding aerosol scattering is desired, or if exclusion of air particles from the air sample is undesirable, then this term can be explicitly included. It will have implications for the measurement of zero intensity and will also place a constraint on the effective optical path length and sensitivity of the measurement. Its calibration would also require a scheme other than the He addition described in the text and at the end of the appendix.

Setting $d I / d t=0$ and $L_{S} / d=1$ in Eq. (A1) yields the following equation for the observed intensity transmitted through the cavity.

$$
I(\lambda)=\frac{k_{S} I_{\text {Source }}(\lambda)}{\frac{1-R(\lambda)}{d}+\alpha_{\text {Ray }}(\lambda)+\sum_{i} \alpha_{i}(\lambda)}
$$


The most convenient definition for the "empty" reference cavity is then the cavity without the absorbing trace gases, but with intensity losses from the mirrors and from Rayleigh scattering. This definition is important because the loss terms due to the mirrors and to Rayleigh scattering are comparable for the apparatus described here, and since it would be cumbersome to record a zero by evacuation of the cavity to vacuum. Although this may seem an unimportant distinction, the empty cavity definition is in fact crucial to the retrieval of concentrations from observed changes in intensity. The "empty" cavity intensity, $I_{0}$, may then be defined as follows.

$I_{0}(\lambda)=\frac{k_{S} I_{\text {Source }}(\lambda)}{\frac{1-R(\lambda)}{d}+\alpha_{\text {Ray }}(\lambda)}$

As noted in previous developments (Paul et al., 2001; Fiedler et al., 2003), the definition of intensity change that both removes the dependence on the coupling of the source intensity and that yields a linear relationship to the sum of the trace gas extinction coefficients is as follows.

$$
\begin{gathered}
\delta I(\lambda)=\frac{I_{0}(\lambda)-I(\lambda)}{I(\lambda)}=\frac{\sum_{i} \alpha_{i}(\lambda)}{\frac{1-R(\lambda)}{d}+\alpha_{\text {Ray }}(\lambda)} \\
\sum_{i} \alpha_{i}(\lambda)=\left(\frac{1-R(\lambda)}{d}+\alpha_{\text {Ray }}(\lambda)\right) \delta I(\lambda)
\end{gathered}
$$

Note that the denominator of the expression for $\delta I$ in Eq. (A4) is not the zero intensity, $I_{0}$, but rather the intensity in the presence of absorbing trace gases, $I$. Any other definition of the intensity change includes terms for the trace gas extinction on both sides of the equation, leading to a nonlinear relationship between the observed intensity change and trace gas extinction. Also note that Eq. (A5) is the same result given by Fiedler et al. (2003), derived from the pass by pass method, with the exception that the Rayleigh scattering of the background air has been explicitly accounted for.

The text describes the calibration of the total cavity loss by measurement of the observed intensity in both $\mathrm{He}\left(I_{\mathrm{He}}\right)$ and dry zero air $\left(I_{\mathrm{ZA}}\right)$. In this case, the wavelength dependent intensity loss due to the mirrors, $(1-R(\lambda)) / d$, may be derived as follows.

$$
\begin{aligned}
I_{\mathrm{He}}(\lambda) & =\frac{k_{S} I_{\text {Source }}(\lambda)}{\frac{1-R(\lambda)}{d}+\alpha_{\mathrm{Ray}}^{\mathrm{He}}(\lambda)} \\
I_{\text {Air }}(\lambda) & =\frac{k_{S} I_{\text {Source }}(\lambda)}{\frac{1-R(\lambda)}{d}+\alpha_{\text {Ray }}^{\text {Air }}(\lambda)}
\end{aligned}
$$

Taking the ratio of $I_{\mathrm{Air}}(\lambda)$ to $I_{\mathrm{He}}(\lambda)$ and solving for the mirror loss term, $(1-R(\lambda)) / d$, gives the following expression

$$
\frac{1-R(\lambda)}{d}=\frac{\left(\frac{I_{\mathrm{Air}}}{I_{\mathrm{He}}}\right) \alpha_{\mathrm{Ray}}^{\mathrm{Air}}-\alpha_{\mathrm{Ray}}^{\mathrm{He}}}{1-\frac{I_{\mathrm{Air}}}{I_{\mathrm{He}}}}
$$

Since Rayleigh scattering cross sections for $\mathrm{He}$ and air are well known, this calibration scheme provides a measurement of the cavity loss.

Acknowledgements. We thank Karl Feierabend for his assistance in synthesizing glyoxal. We thank Rich McLaughlin for machining custom mirror mounts for the IBBCEAS instrument. We thank Susan Solomon for the loan of the InSpectrum 150. We thank Rainer Volkamer and Bill Dube for useful discussions. RAW acknowledges support from the National Research Council Research Associateship Program. This work was funded in part by NOAA's Health of the Atmosphere and Atmospheric Chemistry and Climate programs.

Edited by: Y. Rudich

\section{References}

Ball, S. M. and Jones, R. L.: Broad-band cavity ring-down spectroscopy, Chem. Rev., 103, 5239-5262, 2003.

Ball, S. M., Langridge, J. M., and Jones, R. L.: Broadband cavity enhanced absorption spectroscopy using light emitting diodes, Chem. Phys. Lett., 398, 68-74, 2004.

Bandow, H., Washida, N., and Akimoto, H.: Ring-cleavage reactions of aromatic hydrocarbons studied by FT-IR spectroscopy: 1. Photooxidation of toluene and benzene in the $\mathrm{NO}_{x}$-air system, B. Chem. Soc. Jpn., 58, 2531-2540, 1985.

Bodhaine, B. A., Wood, N. B., Dutton, E. G., and Slusser, J. R.: On Rayleigh optical depth calculations, J. Atmos. Ocean. Tech., 16, 1854-1861, 1999.

Brown, S. S., Ravishankara, A. R., and Stark, H.: Simultaneous kinetics and ring-down: Rate coefficients from single cavity loss temporal profiles, J. Phys. Chem.-US A, 104, 7044-7052, 2000.

Carter, W. P. L. and Atkinson, R.: Development and evaluation of a detailed mechanism for the atmospheric reactions of isoprene and $\mathrm{NO}_{\mathrm{x}}$, Int. J. Chem. Kinet., 28, 497-530, 1996.

Chen, Y. Q. and Zhu, L.: Wavelength-dependent photolysis of glyoxal in the 290-420 nm region, J. Phys. Chem.-US A, 107, 46434651, 2003.

Dube, W. P., Brown, S. S., Osthoff, H. D., Nunley, M. R., Ciciora, S. J., Paris, M. W., McLaughlin, R. J., and Ravishankara, A. R.: Aircraft instrument for simultaneous, in situ measurement of $\mathrm{NO}_{3}$ and $\mathrm{N}_{2} \mathrm{O}_{5}$ via pulsed cavity ring-down spectroscopy, Rev. Sci. Instrum., 77, 034101, doi:10.1063/1.2176058, 2006.

Feierabend, K. J., Zhu, L., Talukdar, R. K., and Burkholder, J. B.: Rate coefficients for the $\mathrm{OH}+\mathrm{HC}(\mathrm{O}) \mathrm{C}(\mathrm{O}) \mathrm{H}$ (glyoxal) reaction between 210 and 390 K, J. Phys. Chem.-US A, 112, 73-82, 2008.

Fick, J., Pommer, L., Nilsson, C., and Andersson, B.: Effect of $\mathrm{OH}$ radicals, relative humidity, and time on the composition of the products formed in the ozonolysis of alpha-pinene, Atmos. Environ., 37, 4087-4096, 2003.

Fiedler, S. E., Hese, A., and Ruth, A. A.: Incoherent broad-band cavity-enhanced absorption spectroscopy, Chem. Phys. Lett., 371, 284-294, 2003.

Flad, J. E., Brown, S. S., Burkholder, J. B., Stark, H., and Ravishankara, A. R.: Absorption cross sections for the $\tilde{A}^{2} \mathrm{~A}$ " $\left(0,9^{\circ}, 0\right) \longleftarrow \mathrm{X}^{2} \mathrm{~A}^{\prime}\left(0,0^{1}, 0\right)$ band of the HCO radical Physical Chemistry, Chem. Phys., 8, 3636-3642, 2006. 
Francois, S., Perraud, V., Pflieger, M., Monod, A., and Wortham, H.: Comparative study of glass tube and mist chamber sampling techniques for the analysis of gaseous carbonyl compounds, Atmos. Environ., 39, 6642-6653, 2005.

Fung, K. and Grosjean, D.: Determination of nanogram amounts of carbonyls as 2,4-dinitrophenylhydrazones by high-performance liquid-chromatography, Anal. Chem., 53, 168-171, 1981.

Gherman, T., Venables, D. S., Vaughan, S., Orphal, J., and Ruth, A. A.: Incoherent broadband cavity-enhanced absorption spectroscopy in the near-ultraviolet: Application to $\mathrm{HONO}$ and $\mathrm{NO}_{2}$, Environ. Sci. Technol., 42, 890-895, 2008.

Goldan, P. D., Kuster, W. C., and Albritton, D. L.: A dynamic dilution system for the production of sub-ppb concentrations of reactive and labile species, Atmos. Environ., 20, 1203-1209, 1986.

Greenblatt, G. D., Orlando, J. J., Burkholder, J. B., and Ravishankara, A. R.: Absorption measurements of oxygen between $330 \mathrm{~nm}$ and $1140 \mathrm{~nm}$, J. Geophys. Res.-Atmos., 95, 18577$18582,1990$.

Grosjean, D., Grosjean, E., and Moreira, L. F. R.: Speciated ambient carbonyls in Rio de Janeiro, Brazil, Environ. Sci. Technol., 36, 1389-1395, 2002.

Grosjean, E., Green, P. G., and Grosjean, D.: Liquid chromatography analysis of carbonyl (2,4-dinitrophenyl)hydrazones with detection by diode array ultraviolet spectroscopy and by atmospheric pressure negative chemical ionization mass spectrometry, Anal. Chem., 71, 1851-1861, 1999.

Harder, J. W. and Brault, J. W.: Atmospheric measurements of water vapor in the 442-nm region, J. Geophys. Res.-Atmos., 102, 6245-6252, 1997.

Harder, J. W., Brault, J. W., Johnston, P. V., and Mount, G. H.: Temperature dependent $\mathrm{NO}_{2}$ cross sections at high spectral resolution, J. Geophys. Res.-Atmos., 102, 3861-3879, 1997.

Hastings, W. P., Koehler, C. A., Bailey, E. L., and De Haan, D. O.: Secondary organic aerosol formation by glyoxal hydration and oligomer formation: Humidity effects and equilibrium shifts during analysis, Environ. Sci. Technol., 39, 8728-8735, 2005.

Ho, S. S. H. and Yu, J. Z.: Determination of airborne carbonyls: Comparison of a thermal desorption/GC method with the standard DNPH/HPLC method, Environ. Sci. Technol., 38, 862-870, 2004.

Huisman, A. J., Hottle, J. R., Coens, K. L., DiGangi, J. P., Galloway, M. M., Kammrath, A., and Keutsch, F. N.: Laser-induced phosphorescence for the in situ detection of glyoxal at part per trillion mixing ratios, Anal. Chem., 80, 5884-5891, 2008.

Jang, M. S. and Kamens, R. M.: Characterization of secondary aerosol from the photooxidation of toluene in the presence of $\mathrm{NO}_{\mathrm{x}}$ and 1-propene, Environ. Sci. Technol., 35, 3626-3639, 2001

Jang, M. S., Czoschke, N. M., Lee, S., and Kamens, R. M.: Heterogeneous atmospheric aerosol production by acid-catalyzed particle-phase reactions, Science, 298, 814-817, 2002.

Kawamura, K., Steinberg, S., and Kaplan, I. R.: Homologous series of C-1-C-10 monocarboxylic acids and C-1-C-6 carbonyls in Los Angeles air and motor vehicle exhausts, Atmos. Environ., 34, 4175-4191, 2000.

Kroll, J. H., Ng, N. L., Murphy, S. M., Flagan, R. C., and Seinfeld, J. H.: Chamber studies of secondary organic aerosol growth by reactive uptake of simple carbonyl compounds, J. Geophys. Res.Atmos., 110, L18808, doi:10.1029/2005JD006004, 2005.
Langford, A. O. and Moore, C. B.: Reaction and relaxation of vibrationally excited formyl radicals, J. Chem. Phys., 80, 4204-4210, 1984.

Langford, A. O., Schofield, R., Daniel, J. S., Portmann, R. W., Melamed, M. L., Miller, H. L., Dutton, E. G., and Solomon, S.: On the variability of the Ring effect in the near ultraviolet: understanding the role of aerosols and multiple scattering, Atmos. Chem. Phys., 7, 575-586, 2007, http://www.atmos-chem-phys.net/7/575/2007/.

Langridge, J. M., Ball, S. M., and Jones, R. L.: A compact broadband cavity enhanced absorption spectrometer for detection of atmospheric $\mathrm{NO}_{2}$ using light emitting diodes, Analyst, 131, 916$922,2006$.

Langridge, J. M., Le Crane, J., Ball, S. M., and Jones, R. J.: Broadband Cavity Enhanced Absorption Spectroscopy: an insitu DOAS for atmospheric measurements, Eos Trans. AGU, 88, Fall Meet. Suppl., Abstract A51H-07, 2007.

Lee, Y. N., Zhou, X., Kleinman, L. I., Nunnermacker, L. J., Springston, S. R., Daum, P. H., Newman, L., Keigley, W. G., Holdren, M. W., Spicer, C. W., Young, V., Fu, B., Parrish, D. D., Holloway, J., Williams, J., Roberts, J. M., Ryerson, T. B., and Fehsenfeld, F. C.: Atmospheric chemistry and distribution of formaldehyde and several multioxygenated carbonyl compounds during the 1995 Nashville Middle Tennessee Ozone Study, J. Geophys. Res.-Atmos., 103, 22449-22462, 1998.

Liggio, J., Li, S. M., and McLaren, R.: Reactive uptake of glyoxal by particulate matter, J. Geophys. Res.-Atmos., 110, D10304, doi:10.1029/2004JD005113, 2005.

Munger, J. W., Jacob, D. J., Daube, B. C., Horowitz, L. W., Keene, W. C., and Heikes, B. G.: Formaldehyde, glyoxal, and methylglyoxal in air and cloudwater at a rural mountain site in Central Virginia, J. Geophys. Res.-Atmos., 100, 9325-9333, 1995.

Osthoff, H. D., Brown, S. S., Ryerson, T. B., Fortin, T. J., Lerner, B. M., Williams, E. J., Pettersson, A., Baynard, T., Dube, W. P., Ciciora, S. J., and Ravishankara, A. R.: Measurement of atmospheric $\mathrm{NO}_{2}$ by pulsed cavity ring-down spectroscopy, J. Geophys. Res.-Atmos., 111, D12305, doi:10.1029/2005JD006942, 2006.

Paul, J. B., Lapson, L., and Anderson, J. G.: Ultrasensitive absorption spectroscopy with a high-finesse optical cavity and off-axis alignment, Appl. Optics, 40, 4904-4910, 2001.

Platt, U., Perner, D., and Patz, H. W.: Simultaneous measurement of atmospheric $\mathrm{CH}_{2} \mathrm{O}, \mathrm{O}_{3}$, and $\mathrm{NO}_{2}$ by differential opticalabsorption, J. Geophys. Res.-Oc. Atm., 84, 6329-6335, 1979.

Read, K. A., Mahajan, A. S., Carpenter, L. J., Evans, M. J., Faria, B. V. E., Heard, D. E., Hopkins, J. R., Lee, J. D., Moller, S. J., Lewis, A. C., Mendes, L., McQuaid, J. B., Oetjen, H., SaizLopez, A., Pilling, M. J., and Plane, J. M. C.: Extensive halogenmediated ozone destruction over the tropical Atlantic Ocean, Nature, 453, 1232-1235, 2008.

Sander, S. P., Friedl, R. R., Golden, D. M., Kurylo, M. J., Moortgat, G. K., Keller-Rudek, H., Wine, P. H., Ravishankara, A. R., Kolb, C. E., Molina, M. J., Finlayson-Pitts, B. J., Huie, R. E., and Orkin, V. L.: Chemical Kinetics and Photochemical Data for Use in Atmospheric Studies, Evaluation Number 15, JPL Publication 06-2, Jet Propulsion Laboratory, Pasadena, USA, 2006.

Scherer, J. J., Paul, J. B., OKeefe, A., and Saykally, R. J.: Cavity ringdown laser absorption spectroscopy: History, development, and application to pulsed molecular beams, Chem. Rev., 97, 25- 
51, 1997.

Seinfeld, J. H. and Pankow, J. F.: Organic atmospheric particulate material, Annu. Rev. Phys. Chem., 54, 121-140, 2003.

Shardanand, S. and Rao, A. D. P.: Absolute Rayleigh scattering cross sections of gases and freons of stratospheric interest in the visible and ultraviolet regions, NASA Technical Note, 1977.

Sneep, M. and Ubachs, W.: Direct measurement of the Rayleigh scattering cross section in various gases, J. Quant. Spectrosc. Ra., 92, 293-310, 2005.

Spaulding, R. S., Talbot, R. W., and Charles, M. J.: Optimization of a mist chamber (cofer scrubber) for sampling water-soluble organics in air, Environ. Sci. Technol., 36, 1798-1808, 2002.

Spaulding, R. S., Schade, G. W., Goldstein, A. H., and Charles, M. J.: Characterization of secondary atmospheric photooxidation products: Evidence for biogenic and anthropogenic sources, J. Geophys. Res.-Atmos., 108, 4247, doi:10.1029/2002JD002478, 2003.

Tomasi, C., Vitale, V., Petkov, B., Lupi, A., and Cacciari, A.: Improved algorithm for calculations of Rayleigh-scattering optical depth in standard atmospheres, Appl. Optics, 44, 3320-3341, 2005.

Triki, M., Cermak, P., Mejean, G., and Romanini, D.: Cavityenhanced absorption spectroscopy with a red LED source for $\mathrm{NO}_{\mathrm{x}}$ trace analysis, Appl. Phys. B-Laser O., 91, 195-201, 2008.

Tuazon, E. C., Atkinson, R., Macleod, H., Biermann, H. W., Winer, A. M., Carter, W. P. L., and Pitts, J. N.: Yields of glyoxal and methylglyoxal from the $\mathrm{NO}_{\mathrm{x}}$-air photooxidations of toluene and m-xylene and p-xylene, Environ. Sci. Technol., 18, 981-984, 1984.

Vandaele, A. C., Hermans, C., Fally, S., Carleer, M., Colin, R., Merienne, M. F., Jenouvrier, A., and Coquart, B.: Highresolution Fourier transform measurement of the $\mathrm{NO}_{2}$ visible and near-infrared absorption cross sections: Temperature and pressure effects, J. Geophys. Res.-Atmos., 107, 4348, doi:10.1029/2001JD000971, 2002.
Venables, D. S., Gherman, T., Orphal, J., Wenger, J. C., and Ruth, A. A.: High sensitivity in situ monitoring of $\mathrm{NO}_{3}$ in an atmospheric simulation chamber using incoherent broadband cavityenhanced absorption spectroscopy, Environ. Sci. Technol., 40, 6758-6763, 2006.

Volkamer, R., Molina, L. T., Molina, M. J., Shirley, T., and Brune, W. H.: DOAS measurement of glyoxal as an indicator for fast VOC chemistry in urban air, Geophys. Res. Lett., 32, L08806, doi:10.1029/2005GL022616, 2005a.

Volkamer, R., Spietz, P., Burrows, J., and Platt, U.: High-resolution absorption cross-section of glyoxal in the UV-vis and IR spectral ranges, J. Photoch. Photobio. A., 172, 35-46, 2005 b.

Volkamer, R., Martini, F. S., Molina, L. T., Salcedo, D., Jimenez, J. L., and Molina, M. J.: A missing sink for gas-phase glyoxal in Mexico City: Formation of secondary organic aerosol, Geophys. Res. Lett., 34, L19807, doi:10.1029/2007GL030752, 2007.

Wittrock, F., Richter, A., Oetjen, H., Burrows, J. P., Kanakidou, M., Myriokefalitakis, S., Volkamer, R., Beirle, S., Platt, U., and Wagner, T.: Simultaneous global observations of glyoxal and formaldehyde from space, Geophys. Res. Lett., 33, L16804, doi:10.1029/2006GL026310, 2006.

Yu, J. Z., Jeffries, H. E., and Lelacheur, R. M.: Identifying airborne carbonyl-compounds in isoprene atmospheric photooxidation products by their PFBHA oximes using gas-chromatography ion-trap mass-spectrometry, Environ. Sci. Technol., 29, 19231932, 1995.

Zhu, L., Kellis, D., and Ding, C. F.: Photolysis of glyoxal at 193, 248, 308 and 351 nm, Chem. Phys. Lett., 257, 487-491, 1996. 